\title{
Grafismo rupestre postpaleolítico en la Sierra de Atapuerca (Burgos): Salón del Coro, Galería del Silo, Galería Baja, Galería de las Estatuas y Cueva del Silo
}

\author{
Marcos García díez ${ }^{*}$, Josep Martín I Uixan**, Ana Isabel Ortega *** \\ Y Miguel ÁNGel MARTíN ${ }^{\star \star \star *}$
}

\begin{abstract}
RESUMEN
ABSTRACT

La primera fase de realización de trabajos de prospección, estudio y análisis del arte rupestre del Complejo Kárstico Cueva Mayor.-Cueva del Silo de la Sierra de Atapuerca, centrados en la totalidad del recorrido subterráneo, a excepción de la conocida Galería del Sílex, aporta nuevos documentos de arte postpaleolítico. Junto a ellos y a la revisión de evidencias publicadas a principios del siglo pasado, se ofrece una nueva visión de la distribución del arte rupestre $y$ se valora el hecho gráfico en relación con otro tipo de evidencias arqueológicas.

The first phase of performing of prospection, study and analysis of the rock art of the Complejo Kárstico de Cueva Mayor-Cueva del Silo of Sierra de Atapuerca, centered in the totality of the subterranean space, excepting the known Galería del Silex, provide new documents of postpalaeolithic art. Along with them and with the revision of evidences published in the beginning of the twentieth century, it is showed a new vision of the distribution of the rock art and it is valued the graphic evidence in relation with other type of archaeological evidences.

* Departamento de Geografía, Prehistoria y Arqueología. Universidad del País Vasco. cl Tomás y Valiente $s / n$. 01006 Vitoria

** Laboratorio de Arqueología. Universidad Rovira i Virgili. Plaza Imperial Tarraco 1. 43005 Tarragona

*** Área de Páleontología. Departamento de Ciencias Históricas y Geografía. Facultad de Humanidades y Ciencias de la Educación. Universidad de Burgos. Crta. Villadiego s/n. 09001 Burgos

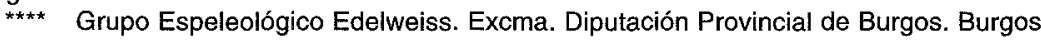




\section{PALABRAS CLAVE \\ Arte rupestre, post-paleolítico, \\ pinturas, grabados. \\ KEY WORDS \\ Rock art, postpalaeolithic, paintings, engravings.}

\section{ENTORNO GEOGRÁFICO, GEOMORFOLÓGICO Y GEOLÓGICO}

La Sierra de Atapuerca se localiza a unos $15 \mathrm{~km}$ al Este de la ciudad de Burgos. Corresponde a una pequeña elevación, cuya mayor cota es la cumbre del San Vicente con 1.081 m.s.n.m. Constituye la estribación más noroccidental del Sistema Ibérico, sirviendo de enlace entre las Cuencas del Duero y del Ebro y las estribaciones meridionales de la Cordillera Cantábrica. Tectónicamente se corresponde con un anticlinal tumbado que se desarrolla en materiales mesozoicos del Cretácico superior (principalmente calizas y dolomías). En los bordes de la sierra se detectan conglomerados calizos y arcillas rojas del Oligoceno. La superficie de erosión localizada en su cumbre, que afecta a las calizas cretácicas, pertenece al Mioceno medio (ITGE, 1997).

Se corresponde con un paisaje medianamente accidentado donde destaca la sierra respecto al valle fluvial del Arlanzón. En su modelado kárstico contrasta la escasa relevancia de formas exokársticas (lapiaz y dolinas principalmente), probablemente desmanteladas desde el Oligoceno hasta el Neógeno, con el gran desarrollo de formas endokársticas, que evolucionaron en profundidad en paralelo al encajanamiento del nivel de base de la Cuenca del Duero. Los depósitos gravitacionales y la erosión permitirán la accesibilidad a las cavidades desde el Pleistoceno Inferior. El relleno de las zonas de entrada por depósitos detríticos se produce desde momentos infero-pleistocénicos hasta el Holoceno.

\section{EL SISTEMA KÁRSTICO DE CUEVA MAYOR-CUEVA DEL SILO: APUNTES ESPELEOLÓGICOS Y ARQUEOLÓGICOS}

El Sistema Cueva Mayor-Cueva del Silo, con sus $3.700 \mathrm{~m}$ de desarroIlo topografiados, es una de las mayores cavidades conocidas en la Cuenca del Duero (Martín, Domingo y Antón, 1981). Si bien en la actualidad cuenta con las dos entradas citadas, en la Prehistoria reciente poseía un acceso directo, hoy obstruido, a la Galería del Sílex. De hecho, durante el Holoceno, representaban tres cavidades cuya utilización estuvo claramente diferenciada por los grupos humanos. 
La cavidad se estructura en tres niveles distintos, en donde Cueva Mayor da acceso a los dos superiores, en tanto que Cueva del Silo permite el ingreso al nivel más bajo del Sistema.

La entrada de Cueva Mayor, también conocida como Cueva de Atapuerca, se abre en el fondo de una fractura, dando acceso a un cómodo Portalón. Sus rellenos, objeto de diferentes excavaciones, han puesto de manifiesto ocupaciones puntuales de época altomedieval y tardo-romana, así como una secuencia continua desde el Bronce Final al Eneolítico.

El cono de derrubios originado en Cueva Mayor, de $34 \mathrm{~m}$ de desnivel desde el borde de la dolina ( $23 \mathrm{~m}$ si tan sólo se considera desde el zócalo de la puerta actual de entrada), facilita el acceso a una amplia galería de dirección SSE-NNW, cuyo primer tramo, conocido como Salón del Coro, se ve afectado por grandes desprendimientos clásticos de tamaño decamétrico. En este recinto han sido recogidos abundantes materiales cerámicos pertenecientes a la Prehistoria reciente.

Más adelante, tras dejar al W el acceso al nivel intermedio, el conducto recibe el nombre de Galería de las Estatuas, caracterizada por la presencia de grandes estalagmitas y columnas de varios metros de altura. Han sido observados restos humanos y materiales cerámicos prehistóricos, entre los que quizás alguno corresponda a cronologías medievales. También se localizan hoyos de tendencia circular, de tamaño variable, excavados en la arcilla, que deben adscribirse a momentos prehistóricos, mientras que unos pocos, de mayor tamaño, probablemente correspondan a antiguas excavaciones arqueológicas.

El nivel intermedio, de dimensiones sensiblemente menores, está constituido por un mismo conducto que en dirección NNW recibe el nombre de Galería Baja y en dirección SSE el de Galería del Silo.

La Galería Baja también se ve afectada por la presencia de numerosos hoyos excavados, algunos presentan parte de sus paredes concrecionadas, características similares a los anteriormente mencionados y son especialmente numerosos en su primer tercio. En ella se han observado unos pocos materiales cerámicos. En su tramo central se documentan, bajo una potente costra, restos paleontológicos pertenecientes a grandes mamíferos que están relacionados con la presencia de una antigua entrada colmatada, probablemente, durante el Pleistoceno. Los depósitos existentes en el extremo final de esta galería se corresponden con la parte superior del relleno de Trinchera Elefante, yacimiento localizado en la Trinchera del Ferrocarril. 
La Galería del Silo también presenta en su piso, especialmente en su tramo intermedio, numerosos hoyos similares a los de la Galería Baja; los mejor conservados son circulares y algunos poseen sus paredes recubiertas por concreción. Se conservan restos de otras estructuras artificiales de formas elipsoidales, formadas mediante el apelmazamiento de la arcilla hasta adoptar la forma de pequeños «diques» de no más de $30 \mathrm{~cm}$ de altura, estando casi todos recubiertos de una costra de concreción que, al endurecerlos, ha facilitado su conservación. También se localizan restos cerámicos y óseos repartidos por casi toda la galería.

Al final de esta galería, tras el ensanche de la Sala de los Cíclopes, se localiza, en su extremo SW, el Tubo de los Vientos, punto de enlace con la Cueva del Silo, tras la desobstrucción realizada en 1965 por el G. E. Edelweiss. En el extremo SE de la sala, próxima a una antigua entrada colmatada en el Pleístoceno, se abre la Sima de los Huesos, conocida en el siglo pasado como «El Silo», lugar donde se localiza el depósito pleistoceno en el que se han recuperado restos de, al menos, 33 individuos de la especie Homo heidelbergensis.

En 1972, una nueva desobstrucción realizada por el G. E. Edelweiss en el otro extremo del Portalón de Cueva Mayor, permitió el acceso a la Galería del Sílex, cuya entrada original, muy próxima a la de Cueva Mayor, se encuentra cegada desde el Bronce Final, permitiendo ello su conservación intacta hasta su descubrimiento. Se trata del conducto más amplio de toda la cavidad perteneciente al mismo eje del Salón del Coro y Galería de las Estatuas, aunque en este sector alternan las direcciones SSW-NNE y WNW-ESE. Se caracteriza por una abundante litogénesis que le confiere una peculiar belleza y porque los procesos de reexcavación de la cueva son mucho más evidentes, al caminar por pisos falsos de concreción colgados hasta 15 y $20 \mathrm{~m}$ por encima de los puntos bajos de la galería. En su interior se documentaron abundantes materiales cerámicos, restos óseos, manifestaciones gráficas rupestres, estructuras artificiales, explotaciones de sílex y otros restos arqueológicos repartidos por toda la galería (Apellániz y Uribarri, 1976; Apellániz y Domingo, 1987).

La Cueva del Silo era antiguamente conocida como Silo de Valhondo debido a su primitiva entrada, una especie de sima o torca destruida a mediados de siglo pasado por las obras de una cantera. No obstante, la entrada prehistórica no debía impedir el acceso al interior de este enrejado de galerías, con direcciones preferentes SSW-NNE y WNW-ESE, desprovistas de litogénesis, en parte debido a que funcionó como surgencia principal del karst, cuando los niveles superiores ya se encontraban inactivos, originando el nacimiento del río Pico, hoy visible a unos centenares 
de metros, aunque lógicamente a cota más baja. Su menor importancia se ha visto traducida en una indefinición en la denominación de la mayoría de los conductos, por lo que se ha procedido, con fines al presente trabajo, a individualizar dos sectores.

El Sector I se localiza a unos $100 \mathrm{~m}$ al SW de la entrada, casi en el extremo de la gran sala de acceso, en el comienzo de un estrecho conducto que acaba en una pequeña sima.

Desde la entrada de la Cueva del Silo, en dirección SE, parte una amplia galería, con abundantes rellenos clásticos, que se aproxima hacia la Sala de los Cíclopes de Cueva Mayor; tras una amplia sala con enormes bloques se localiza un pequeño conducto de unos $2 \mathrm{~m}$ de altura en el que se localizan las grafías del Sector II. Tanto en este sector como en el anterior no ha sido localizada evidencia arqueológica de cultura material alguna.

\section{HISTORIA DE LA INVESTIGACIÓN}

El conocimiento de evidencias arqueológicas en el Sistema Kárstico Cueva Mayor-Cueva del Silo se remonta a 1868, cuando los ingenieros de minas Pedro Sampayo y Mariano Zuaznávar publican el libro Descripción con planos de la Cueva llamada de Atapuerca (Sampayo y Zuaznávar, 1868). Desde aquel año hasta la actualidad han sido localizados, y estudiados de manera diferencial, materiales paleontológicos, antropológicos y arqueológicos representativos de un amplio espectro cronológico de la Prehistoria.

Las primeras referencias sobre manifestaciones gráficas se refieren a un amplio conjunto de inscripciones atribuidas, las más antiguas, al siglo XIII, aunque, con reservas, se apuntaba que algunas podrían ser árabes (Sampayo y Zuaznávar, 1868: 13). Tras casi cuarenta años, L. March, en 1906 , señala la existencia de un motivo soliforme y otro lunar de cronología, según él, probablemente prehistórica (March, 1906). Dichas referencias, interpretadas nuevamente como símbolos' astronómicos, serán retomadas por J. Carballo (1910), quien amplía el dispositivo gráfico con la descripción de una cabeza de caballo pintada en rojo en el Portalón y «una raya vertical de unos 90 centímetros, cruzada por varios trazos paralelos» (Carballo, 1910: 478), también en rojo, localizada en la Galería del Silo, además de documentar inscripciones de posibles caracteres visigóticos y árabes en otros sectores de la cavidad.

En $1913 \mathrm{H}$. Breuil y H. Obermaier revisan las referencias anteriormente publicadas, tras cuyo análisis desmienten los signos astronómicos, in- 
terpretados ahora como formas naturales de fósiles, y describen la cabeza del Portalón como de oso en vez de caballo. Amplían el panel pintado de la Galería del Silo y dan a conocer motivos geométricos pintados en rojo en el Salón del Coro (Galería Principal), un zigzag grabado en la Galería de las Estatuas y un panel de grabados en la Cueva del Silo (Breuil y Obermaier, 1913; Breuil, 1920).

A partir de las anteriores referencias de principios del siglo pasado, las investigaciones sobre las manifestaciones gráficas de estas cavidades quedarán en un olvido casi absoluto, hasta que en 1965 el Grupo Espeleológico Edelweiss descubre nuevos grabados en la Cueva del Silo ${ }^{1}$ y poco después, en 1972, descubren la Galería del Sílex, cuyas grafías fueron publicadas posteriormente (Apellániz y Uribarri, 1976). En 1978 se descubrirán nuevos paneles en la Galería del Silo y Galería Baja.

En 1997 se inició un estudio, inscrito dentro del proyecto integral de investigación de la Sierra de Atapuerca ${ }^{2}$, que planteaba en una primera fase la localización de las grafías ya publicadas y la prospección sistemática de las paredes del Sistema Cueva Mayor-Cueva del Silo, a excepción de la Galería del Sílex, con el fin de localizar nuevas evidencias. Esta primera fase se da por concluida en la actualidad y los resultados obtenidos se presentan en este trabajo.

\section{DESCRIPCIÓN DE LAS EVIDENCIAS GRÁFICAS}

Dentro del término de grafía se da cabida a todos aquellos elementos que sirven para expresar una idea, un pensamiento, un concepto, es decir, para transmitir información. Desde este punto de vista aceptamos que toda evidencia rupestre, independientemente de la adscripción cronológica, tiene en su génesis la particularidad de querer almacenar, transmitir y/o recuperar información, independientemente del número de receptores potenciales y de los fines que se pretendan. Así entendido, el sistema kárstico de Cueva Mayor-Cueva del Silo cuenta en su interior con grafías rupestres de cronología prehistórica e histórica.

\footnotetext{
Diario de Burgos, miércoles 8 de diciembre de 1965.

Proyecto de Investigación de Atapuerca (PB96-1026-C03-01, 02 y 03) financiado por la Dirección General de Enseñanza Superior del Ministerio de Educación y Ciencia y por la Junta de Castilla y León (para la realización de los trabajos de campo). Codirigido por Juan Luis Arsuaga (Universidad Complutense de Madrid), José María Bermúdez de Castro (Museo Nacional de Ciencias Naturales) y Eudald Carbonell (Universitad Rovira i Virgili de Tarragona).
} 
Relativas a estas últimas, que no serán ahora objeto de estudio, apuntar que se distribuyen por la casi práctica totalidad de la cavidad, dándose las mayores concentraciones en el recorrido medio y final. Los temas se concretan, preferentemente, en fechas, nombres y apellidos de personas y de pueblos de los alrededores. A su vez, se encuentran en la Galería del Silo referencias de tipo religioso y motivos relacionados con la muerte. $\mathrm{Si}$ bien han sido observadas referencias del siglo xv, el núcleo mayor pertenece a un margen cronológico que va desde mediados del siglo XIX a mediados del XX.

En diferentes puntos de la cavidad se observan trazos negros realizados con tizones, son estrechos y de recorrido raramente superior a los 10-15 cm, y ocasionalmente concentraciones de color negro de la misma naturaleza que se distribuyen preferentemente de manera aislada; solamente tienden a aparecer concentrados en el final de la Galería Baja y en el panel de las pinturas de la Galería del Silo. No parece claro en ninguno de los casos que su presencia responda a intereses estéticos, sino más bien a cuestiones relacionadas con el tránsito u observación de determinadas superficies. Su cronología, así como la posible relación con las manifestaciones gráficas, nos es desconocida.

A continuación se presentan tanto aquellas manifestaciones (fig. 1) que tradicionalmente han sido consideradas como prehistóricas como las nuevas que consideramos, a priori, pertenecientes a tal espectro cronológico.

\subsection{Cueva Mayor}

Se han documentado evidencias gráficas en 4 puntos del sector kárstico denominado Cueva Mayor: Salón del Coro de la Galería Principal, Galería del Silo, Galería Baja y Galería de las Estatuas.

\subsubsection{Salón del Coro de la Galería Principal}

Sobre un gran bloque calcáreo dispuesto verticalmente, cubierto por arcilla de descalcificación, de morfología sinuosa e irregular debido a la presencia de huellas de corriente y al desprendimiento de plaquetas, se encuentran cuatro motivos pintados en color rojo asociados entre sí (fig. 2, foto 1).

GP.1. Se sitúa a $186 \mathrm{~cm}$ del suelo actual. Formalmente representa una morfología tendente a rectangular dividida en su interior por dos trazos verticales, conformando una división interna del espacio en tres unidades 


\section{Karst de la Sierra de Atapuerca}

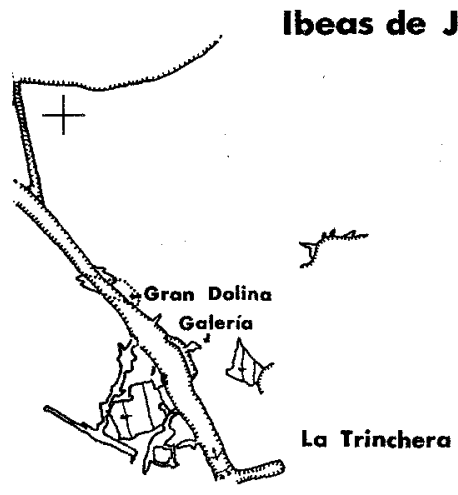

\section{Ibeas de Juarros - Atapuerca. Burgos (España)}

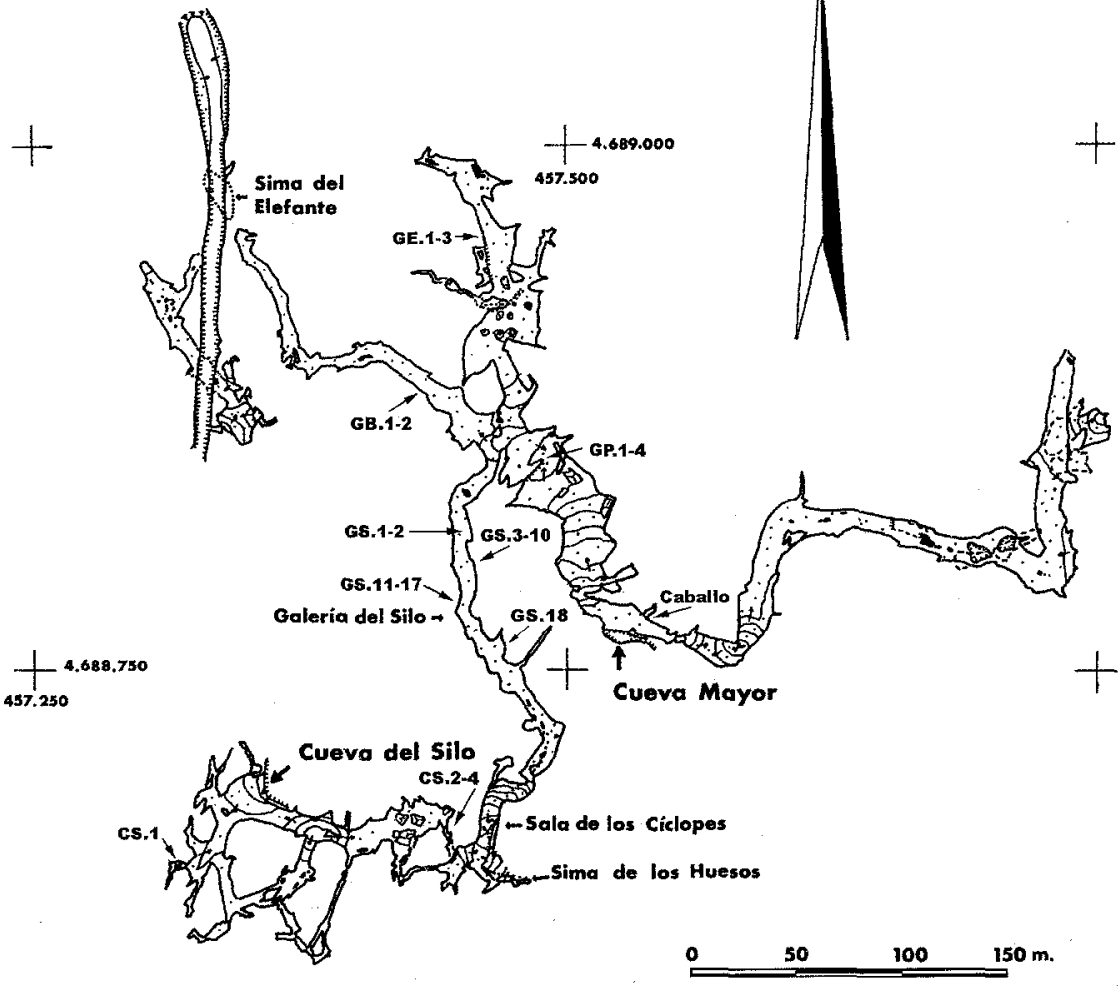

G. E. Edelweiss

Fig. 1. Topografía del Complejo Kárstico y localización de las manifestaciones gráficas. 


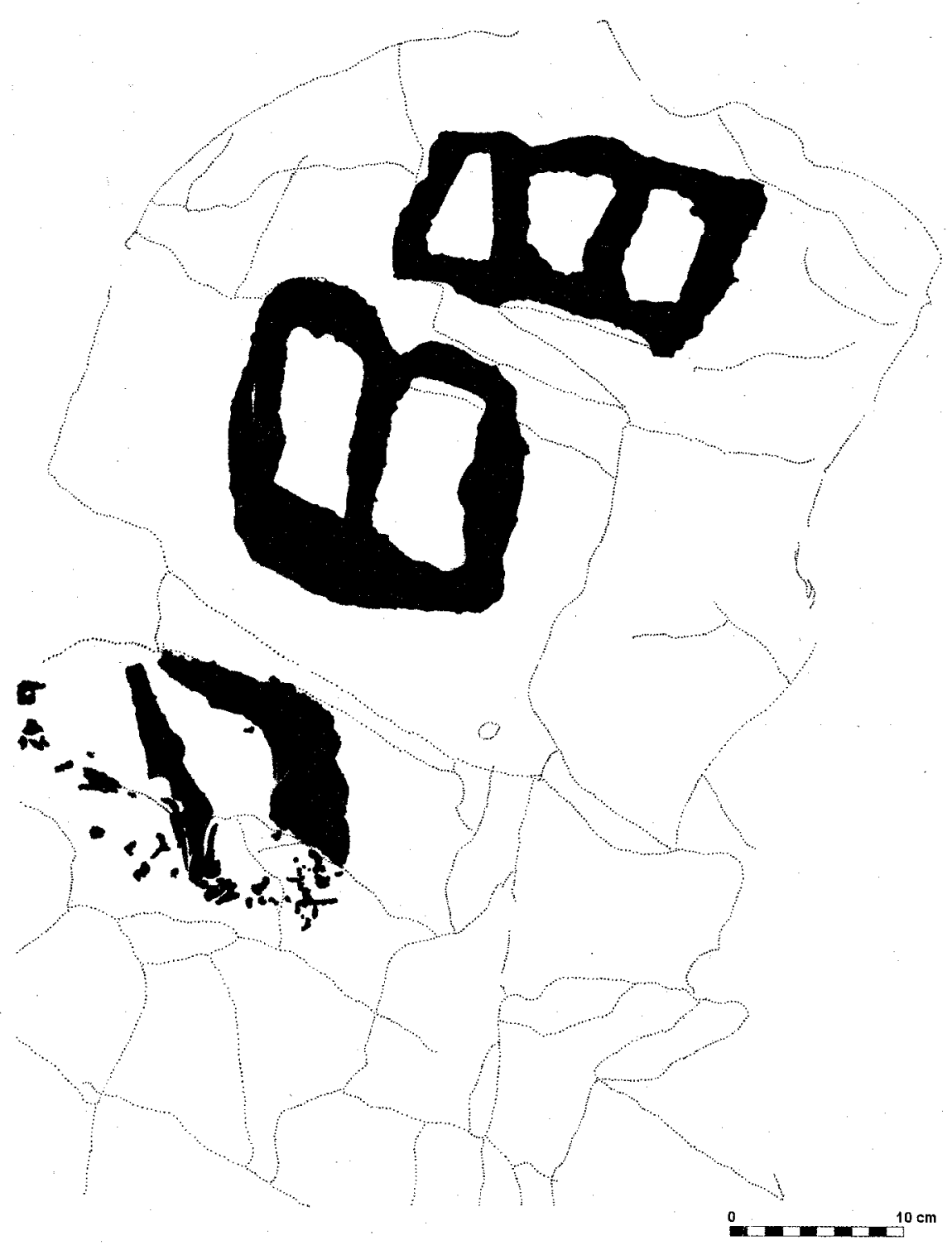

Fig. 2. Motivos GP.1 a GP.4 del Salón del Coro. 


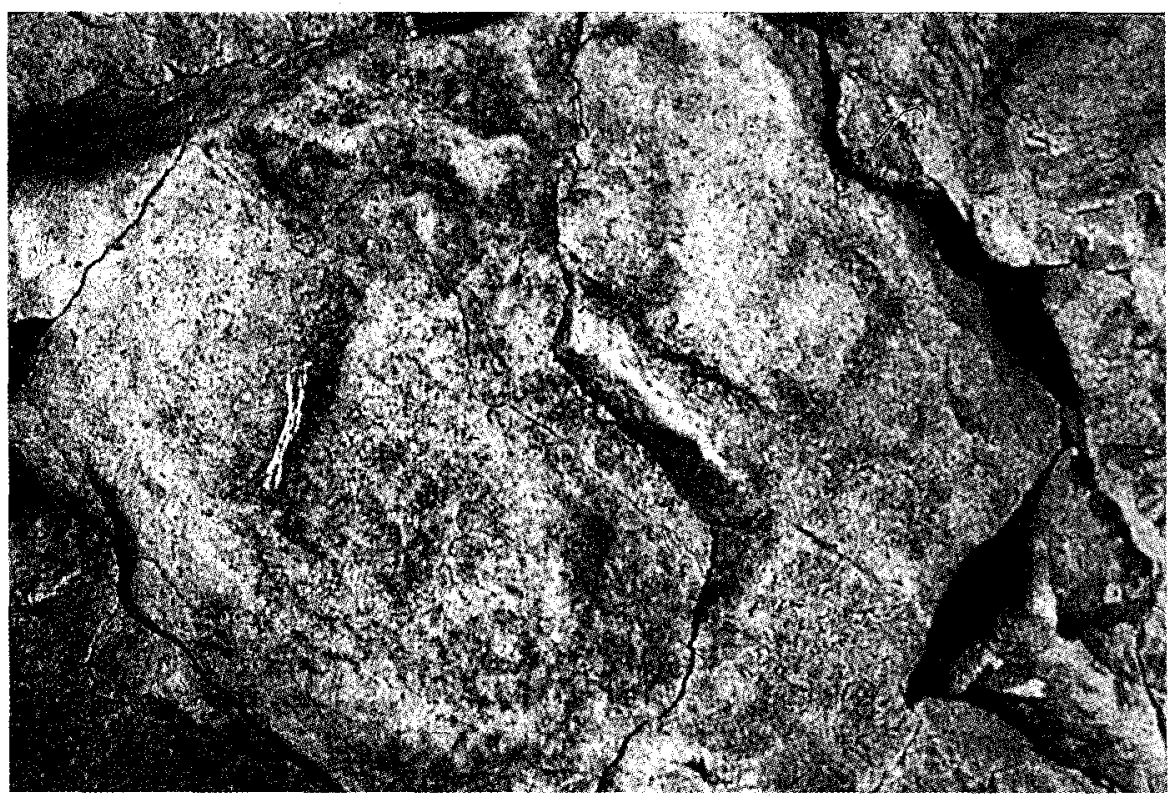

Foto 1. Motivos GP.1 y GP.2 del Salón del Coro.

cuadrangulares que presentan la parte superior convexa. Mide $19,5 \mathrm{~cm}$ de anchura máxima y $10 \mathrm{~cm}$ de altura máxima. El grosor de la línea varía entre 1,5 y $2 \mathrm{~cm}$. La parte central muestra una coloración tenue debido al deficiente estado de conservación en que se encuentra.

GP.2. $2 \mathrm{~cm}$ por debajo del motivo GP.1 y a $166 \mathrm{~cm}$ del suelo se localiza un motivo de caracteres técnicos similares al anterior. Muestra una morfología tendente a cuadrangular dividida en su interior por un trazo vertical, que presenta su lado superior biconvexo. La anchura y altura máxima son similares, $17 \mathrm{~cm}$. El trazo del lateral izquierdo presenta tres trazos grabados longitudinalmente, probablemente, con un instrumento metálico en época actual ${ }^{3}$.

GP.3. $4,5 \mathrm{~cm}$ por debajo del anterior y a $149 \mathrm{~cm}$ del suelo se ejecutaron dos líneas oblicuas que tienden a converger por sus partes distales; en la superficie que separa las zonas inferiores se observan, de manera muy tenue, pequeñas zonas con material colorante que, probablemente, conformaron una línea. De ser así, habría que concluir que se diseñó una

3. El interior de los surcos presenta un color muy vívo, falto de pátina alguna. 
morfología triangular, técnicamente similar a los anteriores motivos. La anchura máxima es de $10 \mathrm{~cm}$ y la altura máxima $15 \mathrm{~cm}$.

GP.4. A la izquierda del anterior motivo se observan pequeñas superficies con material colorante rojo, sin llegar a reconocerse morfología definida alguna. La anchura máxima del conjunto es de $6 \mathrm{~cm}$ y la altura de $12 \mathrm{~cm}$.

\subsubsection{Galería del Silo}

El primer conjunto de motivos se encuentra a unos $50 \mathrm{~m}$ del inicio de la galería. Se sitúan en el techo, entre 200 y $240 \mathrm{~cm}$, respectivamente, del suelo. Ambos se observan en la actualidad muy tenuemente debido a la deposición de arcilla de descalcificación sobre el soporte, que provoca un ennegrecimiento de la capa superficial y que tiende a tapar las grafías, acción acrecentada por los depósitos calcíticos tipo «leche lunar». Los caracteres técnicos son similares en ambos: grabado muy fino, con anchura del surco inferior a $0,5 \mathrm{~mm}$ y morfología de sección en " $V$ ».

GS.1. A $2 \mathrm{~m}$ del suelo se grabaron un mínimo de 21 líneas rectilíneas que se disponen entre sí paralela y ortogonalmente (fig. 3). Las relaciones físicas que se generan hacen intuir la conformación, incompleta cuanto menos en la actualidad, de una estructura reticulada en la parte inferior que se une, mediante una línea, a las líneas del nivel superior. La anchura máxima es de $38 \mathrm{~cm}$ y la altura de $22 \mathrm{~cm}$.

GS.2. $110 \mathrm{~cm}$ a la derecha se encuentra un conjunto formado por quince líneas rectilíneas, una curva y una ligeramente sinuosa (fig. 4). Se disponen entre sí de manera paralela, oblicua y ortogonal. Las relaciones físicas que se generan entre líneas conforman un motivo de carácter reticulado. La anchura máxima es de $15 \mathrm{~cm}$ y la altura máxima de $8 \mathrm{~cm}$.

Un segundo conjunto (fig. 5 , foto 2 ) se encuentra, avanzando, a aproximadamente $45 \mathrm{~m}$; se sitúa en la pared izquierda, sobre una superficie calcárea sinuosa - carácter conformado por las huellas de corriente que se presentan muy marcadas - y recubierto por una fina capa de depósitos tipo "leche lunar», que conlleva a una percepción limitada del dispositivo. El panel ocupa una superficie máxima de $85 \mathrm{~cm}$ de anchura y 15 $\mathrm{cm}$ de altura. Los caracteres técnicos son similares en todos ellos: anchura del surco de 0,5 mm y morfología de la sección en "V». Bajo el panel, en el suelo, se localiza una estructura de morfología elipsoidal, muy alterada por el paso de los visitantes, excavada en la arcilla: presenta un diámetro medio variable entre 145 y $160 \mathrm{~cm}$ y una profundidad máxima de $45 \mathrm{~cm}$. 


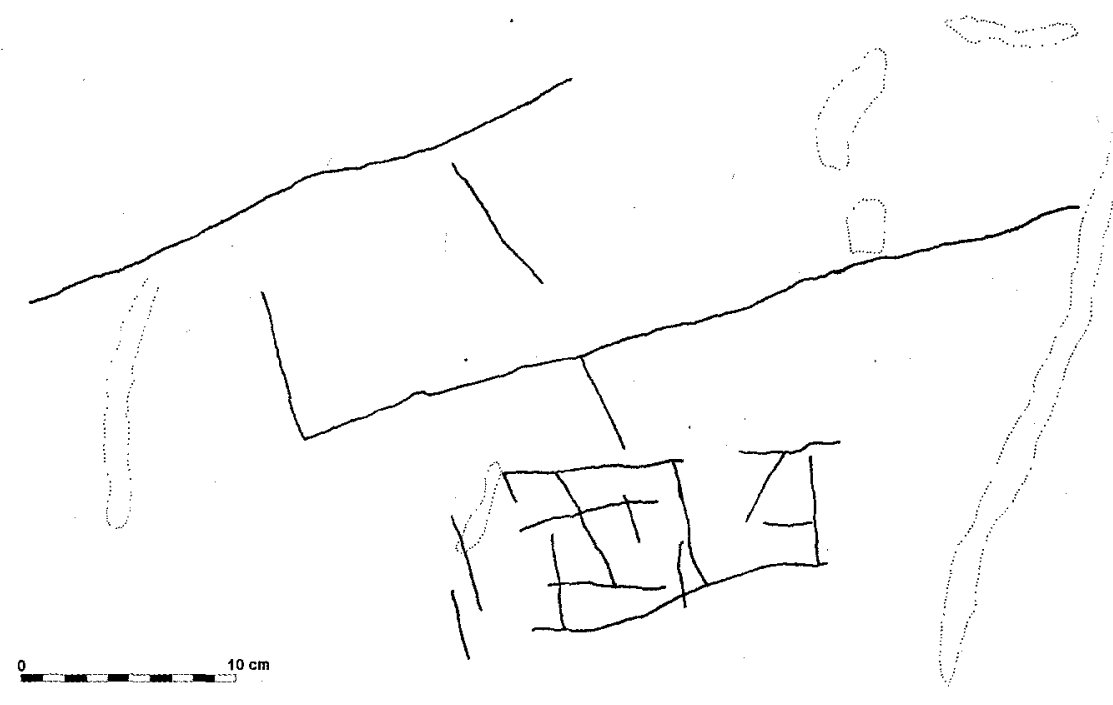

Fig. 3. Motivo GS.1 de la Galería del Silo.

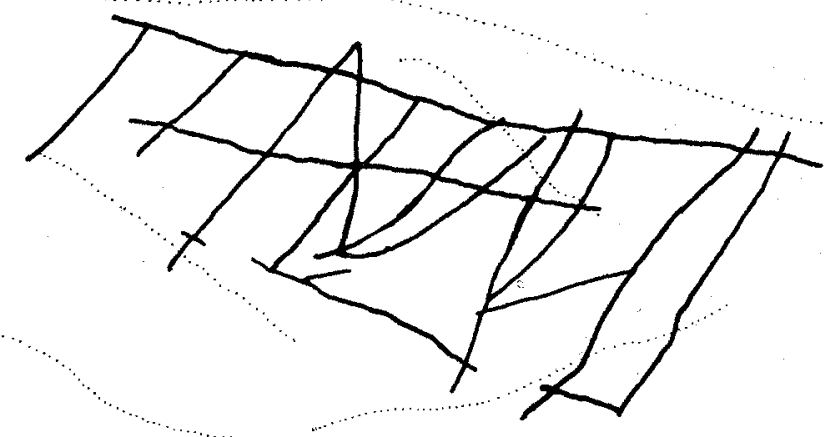

Fig. 4. Motivo GS.2 de la Galería del Silo. 


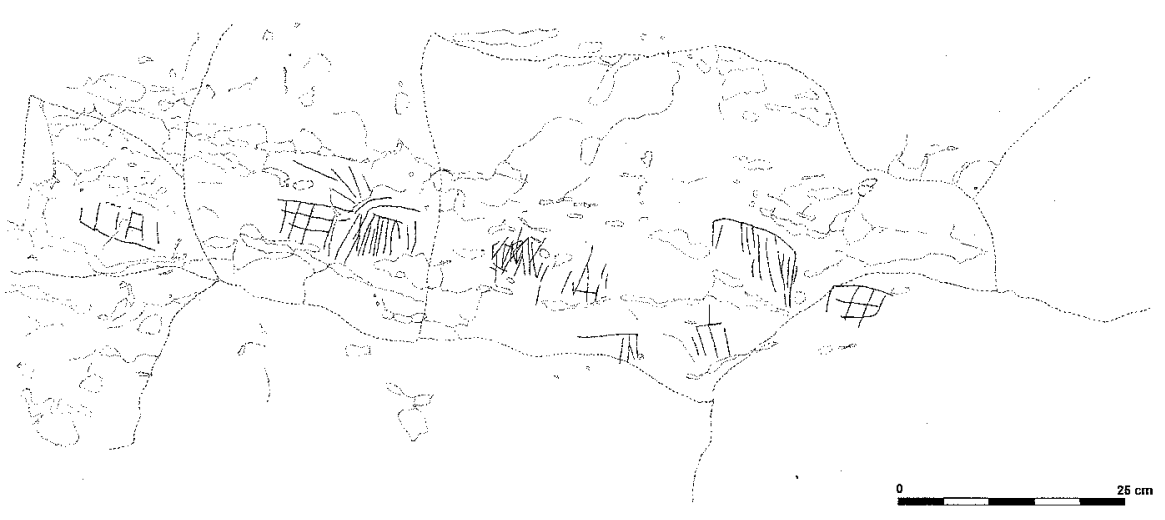

Fig. 5. Motivos GS.3 a GS.10 de la Galería del Silo.

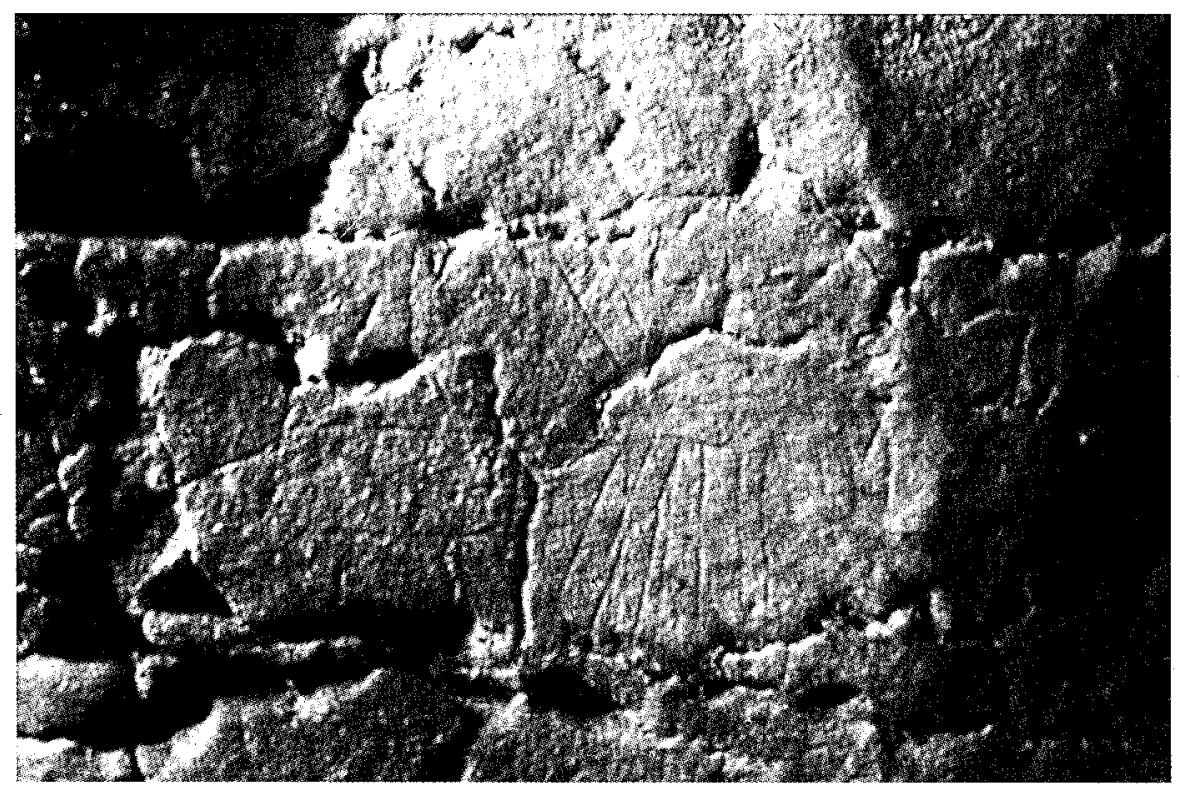

Foto 2. Motivos GS.4 y GS.5 de la Galería del Silo. 
GS.3. A $48 \mathrm{~cm}$ del suelo y en el interior de una huella de corriente, se grabó un conjunto de 9 líneas rectilíneas dispuestas, entre sí, paralela y ortogonalmente. Morfológicamente pudiera ser considerada como una representación parcial de un morfotipo reticulado. La anchura máxima es de $8 \mathrm{~cm}$ y la altura máxima de $3,5 \mathrm{~cm}$.

GS.4. $13 \mathrm{~cm}$ a la derecha del anterior, a $57 \mathrm{~cm}$ del suelo y en el interior de otra huella de corriente, se diseñó una morfología que, al igual que GS.3, puede ser considerada una representación parcial de retícula compuesta por 7 líneas rectilíneas dispuestas entre sí, paralela y ortogonalmente. La anchura máxima es de $6 \mathrm{~cm}$ y la altura de $8 \mathrm{~cm}$.

GS.5. En la misma huella de corriente se grabaron 20 líneas rectilíneas y 2 curvas que se disponen entre sí, gran parte de ellas, oblicua, paralela y ortogonalmente. La asociación entre líneas parece evidenciarse por la relación física que muestran algunas de ellas y por la disposición radial entre una de las líneas curvas y las oblicuas. La anchura y altura máxima es de $11 \mathrm{~cm}$.

En el interior de una nueva huella de corriente se sitúan los motivos (GS.6, 7, 8 y 9) descritos a continuación:

GS.6. $8,5 \mathrm{~cm}$ a la derecha del anterior y a $60 \mathrm{~cm}$ del suelo se encuentra un conjunto de líneas rectilíneas (mínimo de 30) que se disponen, la mayor parte de ellas, paralelas y oblicuamente, tendiendo todas ellas a verticalizarse. Se conectan formando, a veces, morfologías en « $V$ », algunas de ellas invertidas. La anchura máxima es de $13 \mathrm{~cm}$ y la altura máxima de $7 \mathrm{~cm}$.

GS.7. $4 \mathrm{~cm}$ por debajo de GS.6 se grabó un conjunto de 5 líneas rectilíneas dispuestas entre sí paralela, oblicua y ortogonalmente. Todas menos una presentan contacto físico con alguna otra perteneciente al conjunto. Las medidas máximas son $6,5 \mathrm{~cm}$ para la anchura y $3 \mathrm{~cm}$ para la altura.

GS.8. $6 \mathrm{~cm}$ a la derecha se observan 6 líneas rectilíneas dispuestas, algunas de ellas, paralela y ortogonalmente. La anchura máxima es de $3,5 \mathrm{~cm}$ y la altura de $6 \mathrm{~cm}$.

GS.9. Ligeramente a la derecha y a $7 \mathrm{~cm}$ por encima del anterior se grabaron un mínimo de 15 líneas rectilíneas, dispuestas, todas menos una que se opone ortogonalmente a las otras, en paralelo y tendentes a verticalizarse; algunas se encuentran limitadas en su recorrido por la línea horizontal. Las medidas máximas son de $9,5 \mathrm{~cm}$ para la anchura y $7 \mathrm{~cm}$ para la altura. 
Un último motivo grabado del panel se localiza en la parte superior de una nueva huella de corriente que sigue, por la derecha, a la anteriormente descrita.

GS.10. $4 \mathrm{~cm}$ a la derecha del motivo GS.9 se grabaron 7 líneas rectilíneas dispuestas entre sí ortogonalmente. Forman, parcialmente, un motivo reticulado. La anchura máxima es de $6,5 \mathrm{~cm}$ y la altura de $4,5 \mathrm{~cm}$.

Avanzando poco más de 25 metros, en la pared contraria, la derecha, se localizan, en la parte final de un gran friso corrido de varios metros de largo, motivos pintados en rojo (fig. 6 , foto 3 ) que se encuentran en un

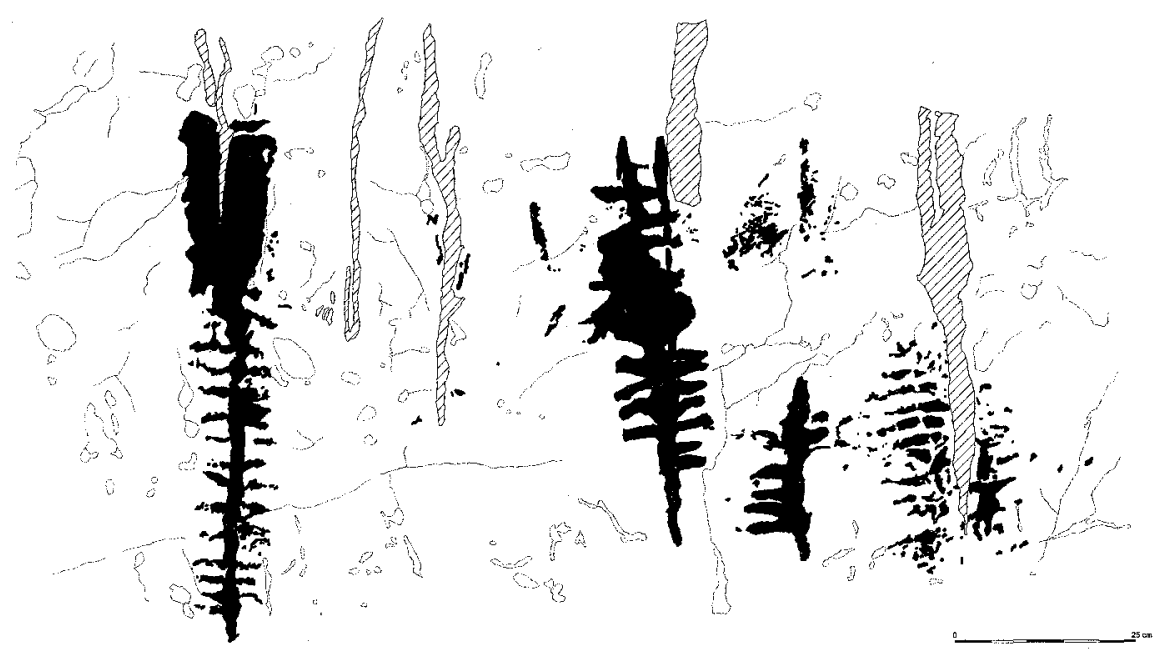

Fig. 6. Motivos GS.11 a GS.16 de la Galería del Silo.

deficiente estado de conservación debido a la circulación, muy tenue pero constante, de agua por capilaridad y al desarrollo de formaciones calcíticas que tienden a enmascarar las grafías. La totalidad del conjunto gráfico se extiende a lo largo de una superficie de $275 \mathrm{~cm}$ de anchura por $80 \mathrm{~cm}$ de altura y se encuentra entre 40 y $100 \mathrm{~cm}$ del suelo; en ella se observan un número destacable de marcas negras que responden, probablemente, a los elementos utilizados en la iluminación. Debajo de éstas, en el suelo de la cavidad, se sitúa una estructura excavada en la arcilla de morfología elipsoidal cuyo diámetro varía entre 140 y $155 \mathrm{~cm}$, siendo la profundidad máxima de $55 \mathrm{~cm}$. 


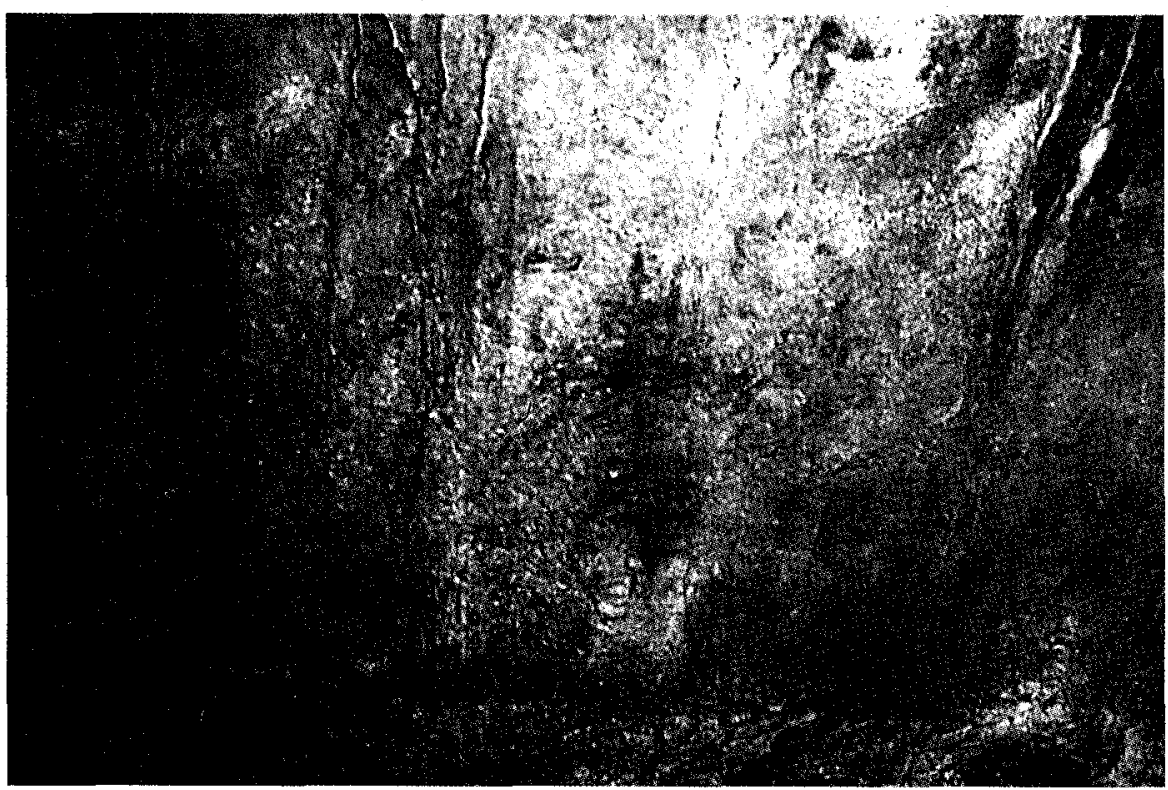

Foto 3. Motivos GS.11 a GS.16 de la Galería del Silo.

GS.11. Es el motivo situado en el extremo derecho del panel. Se encuentra muy afectado por el desarrollo de una formación calcítica que lo atraviesa por el medio. A tenor de lo que en la actualidad puede percibirse, se describe como conjunto de líneas horizontales (un mínimo de 12) tendentes a paralelizarse entre sí. Acompañan a éstas concentraciones de materia colorante que en algún caso pudieron componer líneas. El conjunto presenta una anchura máxima de $28 \mathrm{~cm}$ y un altura máxima de $35 \mathrm{~cm}$.

GS.12. $2 \mathrm{~cm}$ a la izquierda del anterior se observa una línea ancha ( 1,5 a $2 \mathrm{~cm}$ de anchura) vertical de $26 \mathrm{~cm}$ de recorrido, de la cual parten, ortogonalmente, hacia la izquierda 5 líneas (de 4 a $6 \mathrm{~cm}$ de largura) y a la derecha un mínimo de $3(3,5 \mathrm{~cm}$ de media). La estructura gráfica se adscribe al morfotipo de ramiforme. Presenta una anchura máxima de $13 \mathrm{~cm}$ y una altura máxima de $26 \mathrm{~cm}$.

GS.13. $15 \mathrm{~cm}$ por arriba de GS.12 se localizan concentraciones de materia colorante, cuya asociación pudiera corresponder con una morfología hoy en día irreconocible. La anchura máxima del conjunto es de 16 $\mathrm{cm}$ y la altura máxima de $18 \mathrm{~cm}$. 
GS.14. Escasos centímetros a la izquierda de los dos motivos anteriores se encuentra un morfotipo de ramiforme. Se compone de dos largas líneas verticales: de la izquierda, de $57 \mathrm{~cm}$ de recorrido, nace, por la parte inferior del lado derecho, otra de recorrido inferior y ligeramente oblicua. En los laterales de ambas se diseñaron líneas de menor recorrido (de 3,5 a $6 \mathrm{~cm}$ ) que en algunos casos cortan perpendicularmente a las dos centrales. La región media-superior se encuentra muy afectada por la circulación de agua, conformando una zona densa de color en la que se hace especialmente difícil individualizar líneas que con seguridad existieron: el número de líneas mínimas que pueden discriminarse son 15 a la derecha y 9 a la izquierda.

GS.15. Entre el motivo GS.14 y el GS.16 se observan concentraciones de materia colorante que en algún caso pueden ser descritas como líneas, cuanto menos dos de ellas. La anchura máxima del conjunto es de $16 \mathrm{~cm}$ y la altura máxima de $29 \mathrm{~cm}$.

GS.16. $20 \mathrm{~cm}$ a la izquierda del anterior se localiza otro morfotipo de ramiforme muy similar al descrito como GS.14. Presenta un estado de conservación similar a aquel, apareciendo en la zona superior una densa masa de color en la que se hace difícil discriminar líneas. La línea vertical mide $71 \mathrm{~cm}$ de longitud; del contorno derecho se desarrollan un mínimo de 24 líneas de recorrido variable entre 2,5 y $5 \mathrm{~cm}$; del izquierdo, componiendo con la mayor parte de los trazos del otro controno una sola línea, un número mínimo de 22.

GS.17. $140 \mathrm{~cm}$ a la izquierda de GS.16 se halla una concentración de materia colorante de color rojo (fig. 7). Mide $3 \mathrm{~cm}$ de altura máxima y $2 \mathrm{~cm}$ de anchura máxima. Su deficiente estado de conservación dificulta una asignación morfológica.

El último conjunto de motivos se encuentra en una elevada y pequeña galería localizada en lateral izquierdo, a $35 \mathrm{~m}$ del anterior panel. A unos $150 \mathrm{~cm}$ del suelo de ésta y en la pared oeste se encuentra un reducido número de grabados.

GS.18. Sobre una fina película de arcilla de descalcificación, en la actualidad parcialmente desconchada, se grabaron líneas formando motivos envolventes y paralelos. Se ejecutaron mediante técnica digital, surcos anchos y de morfología de sección, poco profunda, en «U», e incisión de surco fino. Su estado de conservación es muy deficiente, dificultándose su observación y documentación.

\subsubsection{Galería Baja}

Los motivos se localizan al poco de iniciar el recorrido de la galería, a escasos $50 \mathrm{~m}$. Se sitúan en la pared izquierda sobre un soporte calcáreo 


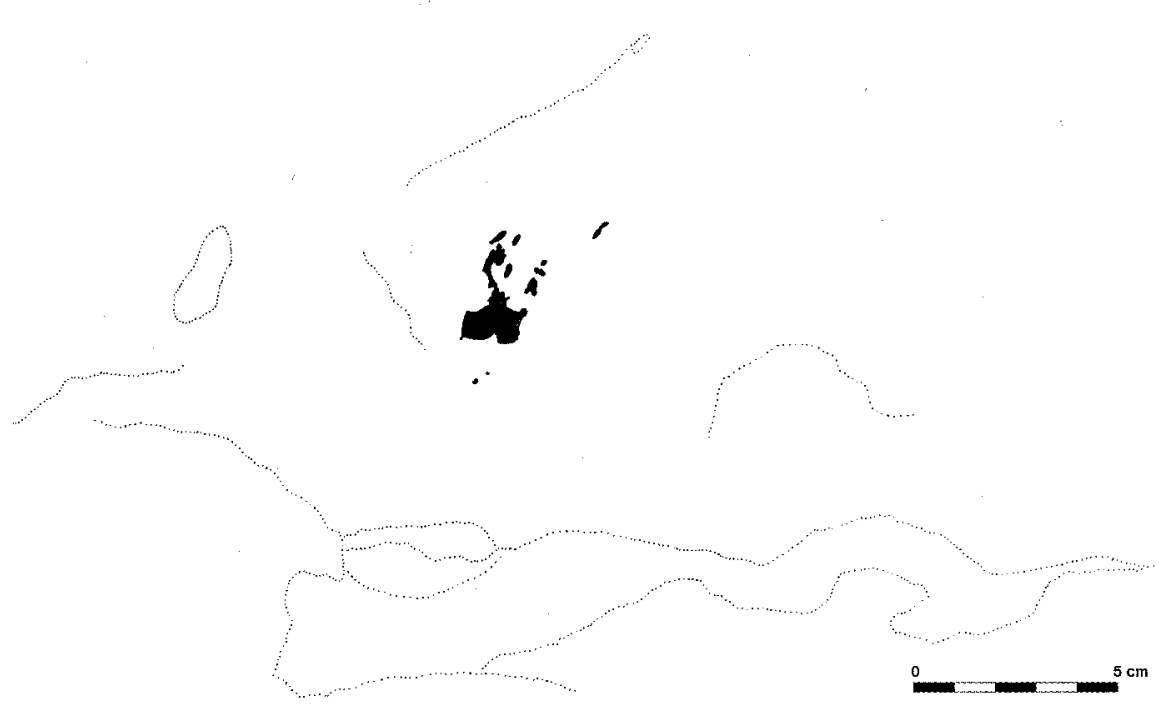

Fig. 7. Motivo GS. 17 de la Galería del Silo.

recubierto por una fina capa de arcilla de descalcificación. Sobre ella, y sobre las grafías, se encuentra un fino depósito calcítico tipo «leche lunar». Ambos comparten caracteres técnicos: grabado muy fino, anchura de trazo no superior a $1 \mathrm{~mm}$ y sección de surco en $« \mathrm{~V} »$.

GB.1. Sobre un plano sub-vertical, de morfología ligeramente cóncava y a $112 \mathrm{~cm}$ del suelo, se grabó un morfotipo reticulado compuesto por 27 líneas rectilíneas dispuestas entre sí paralela y ortogonalmente (fig. 8). La anchura máxima es de $22 \mathrm{~cm}$ y la altura máxima de $12,5 \mathrm{~cm}$.

GB.2. $43 \mathrm{~cm}$ hacia el interior y dispuesto sobre un plano horizontal, el techo de una plataforma, se localiza otro reticulado, parcialmente afectado por formaciones calcíticas, compuesto por 13 líneas rectilíneas paralelas y ortogonales (fig. 9). Las medidas máximas son de $31 \mathrm{~cm}$ para la anchura y $26 \mathrm{~cm}$ para la altura.

\subsubsection{Galería de las Estatuas}

Los tres motivos, situados a unos $75 \mathrm{~m}$ del inicio de la galería, se localizan sobre una pared calcárea de morfología sinuosa, debido a la existencia de huellas de corriente, dispuesta en plano sub-vertical y cubierta por una capa de arcilla producto de la descalcificación. 


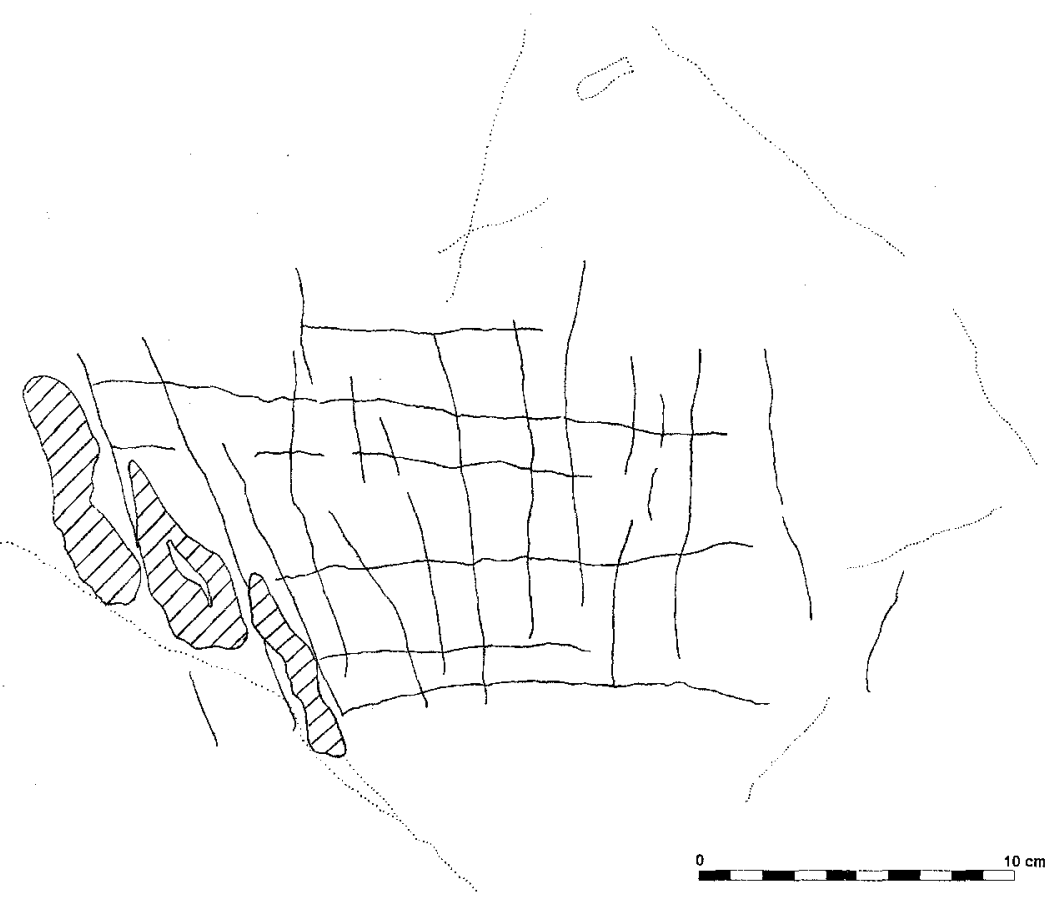

Fig. 8. Motivo GB.1 de la Galería Baja.

GE.1. A $192 \mathrm{~cm}$ del suelo se grabaron, con anchura de $0,5 \mathrm{~cm}$ y morfología de sección en "U», 7 líneas rectilíneas, dispuestas entre sí paralela y ortogonalmente, y una curva situada en la parte superior del motivo (fig. 10). La altura máxima del conjunto es de $27 \mathrm{~cm}$ y la anchura de $15 \mathrm{~cm}$.

GE.2. $184 \mathrm{~cm}$ a la derecha del anterior y a $2 \mathrm{~m}$ del suelo se grabaron 5 líneas quebradas, de longitud variable, que discurren tendiendo a paralelizarse conformando una morfología tipo zigzag (fig. 11). La anchura del surco varía entre 4 y $5 \mathrm{~mm}$, siendo la morfología en «V». La anchura máxima del conjunto es de $53 \mathrm{~cm}$ y la altura de $27 \mathrm{~cm}$.

GE.3. $140 \mathrm{~cm}$ por debajo del anterior motivo se sitúan 18 líneas rectilíneas dispuestas en paralelo (fig. 12), tendiendo la mayor parte a verticalizarse, si bien unas pocas tienden a ser oblicuas a las anteriores. Los caracteres técnicos son similares al motivo GE.2. La anchura máxima del conjunto es de $19 \mathrm{~cm}$ y la altura de $24 \mathrm{~cm}$. 


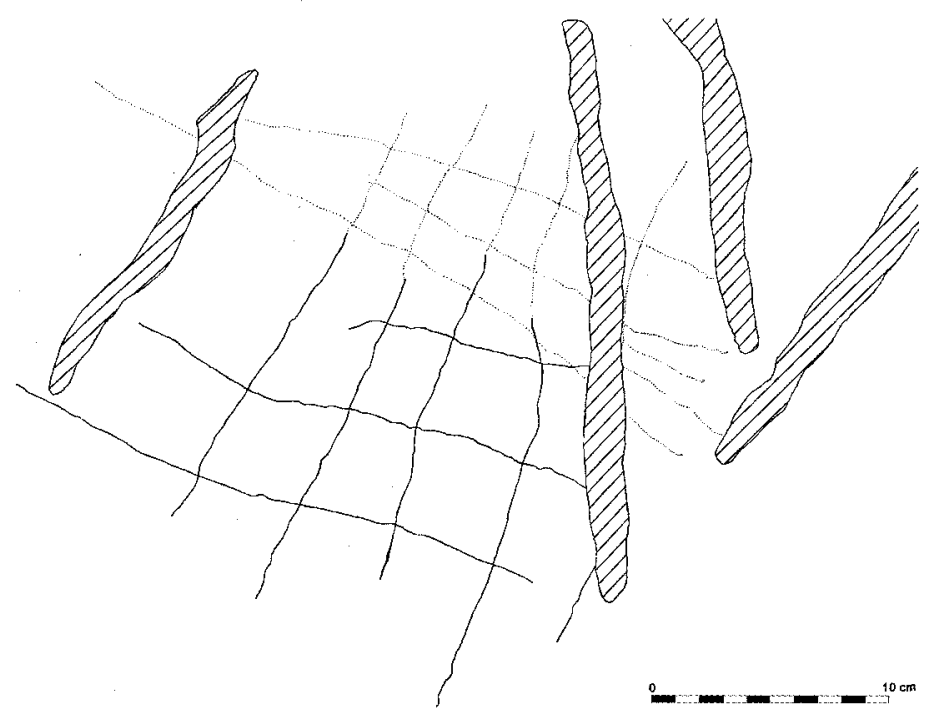

Fig. 9. Motivo GB. 2 de la Galería Baja.

\subsection{Cueva del Silo}

Se han documentado evidencias gráficas en dos puntos del sector kárstico denominado Cueva del Silo, que se han definido como sector I y II.

\subsubsection{Sector I}

En la pared derecha del conducto se sitúa un panel de $230 \mathrm{~cm}$ de anchura y $100 \mathrm{~cm}$ de altura. El soporte es calcáreo, de morfología muy sinuosa conformada por las huellas de corriente, dispuesto verticalmente, presentando un perfil general cóncavo y recubierto de arcilla de descalcificación. La caliza, muy alterada, presenta un aspecto polvoriento.

CS.1. Mediante grabado fino y anchura de trazo variable entre 0,5 y $2 \mathrm{~mm}$ se realizaron líneas rectilíneas y curvas dispuestas entre sí paralela, oblicua y ortogonalmente (fig. 13, foto 4). El conjunto se inscribe en una superficie máxima de $150 \mathrm{~cm}$ de anchura y $80 \mathrm{~cm}$ de altura. De la globalidad, entre la que destacan líneas oblicuas que se unen por sus extremos conformando morfologías en $« \mathrm{~V} »$, pueden individualizarse cuanto menos dos morfotipos: 


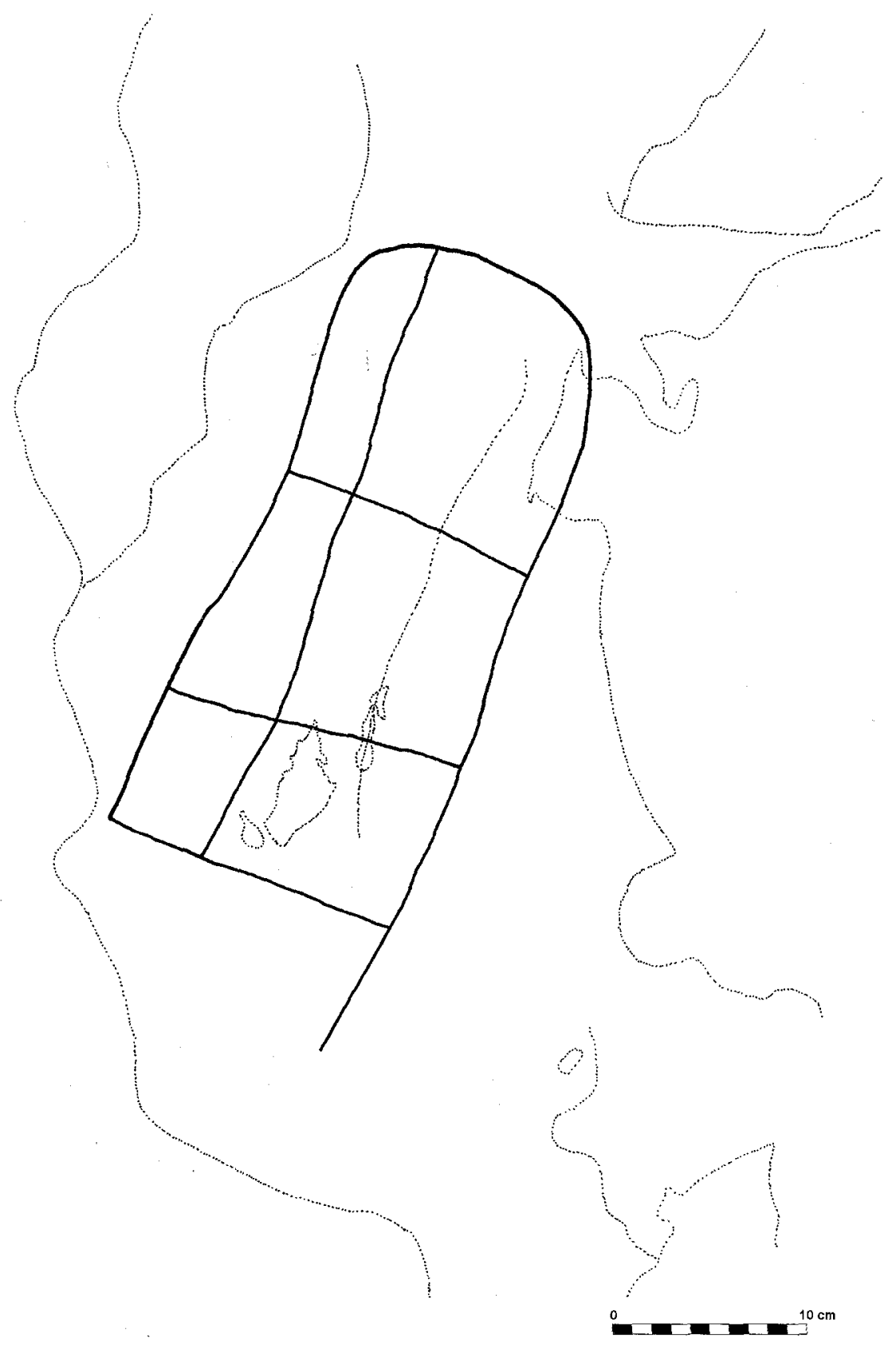

Fig. 10. Motivo GE.1 de la Galeria de las Estatuas. 


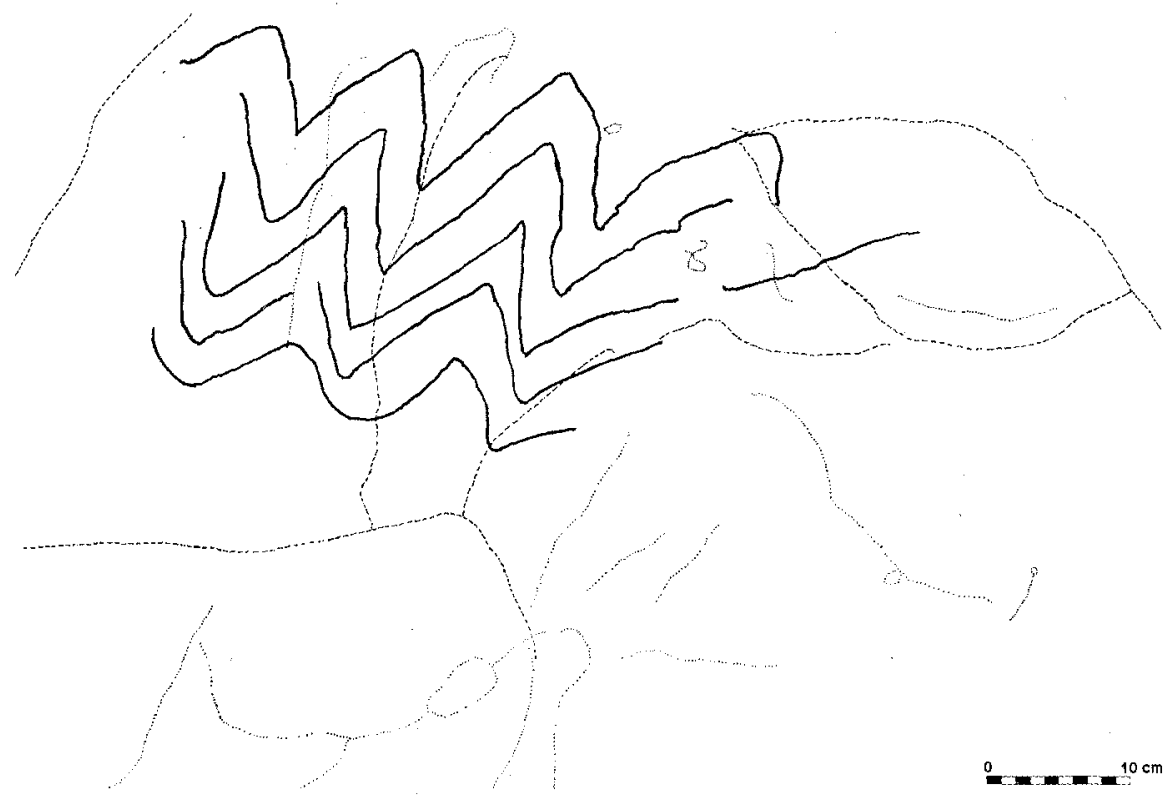

Fig. 11. Motivo GE.2 de la Galería de las Estatuas.

CS.1.1. En la parte superior un motivo elipsoidal de $19 \mathrm{~cm}$ de anchura máxima y $9 \mathrm{~cm}$ de altura máxima. Presenta una línea sagital central de la que surgen, oblicuamente, otras cuyos recorridos se dirigen hacia los contornos. Se inscribe dentro del morfotipo de los foliáceos.

CS.1.2. Bajo el anterior, y un poco hacia la derecha, se sitúa una larga línea horizontal de la que parten, hacia abajo y ortogonalmente, otras. Este conjunto pudiera ser considerado como una representación parcial del morfotipo de parrilla.

\subsubsection{Sector II}

El conjunto se concentra en un tramo donde las paredes sinuosas, por las huellas de corriente, se encuentran recubiertas por una capa de arcilla de descalcificación.

CS.2. A $150 \mathrm{~cm}$ del suelo y en la pared derecha, dispuesta en plano sub-vertical, se localiza un conjunto de surcos rectilíneos grabados que configuran una línea quebrada, una morfología de zigzag (fig. 14). El surco 


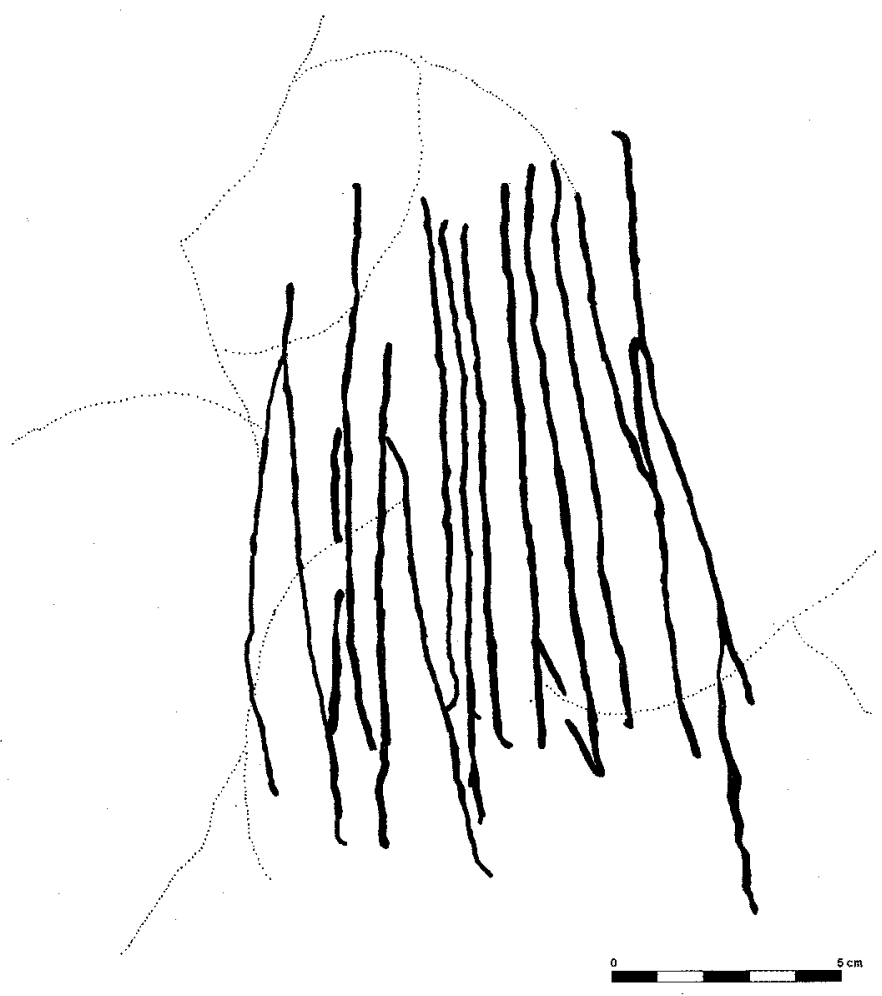

Fig. 12. Motivo GE.3 de la Galería de las Estatuas.

es ancho, de 0,8 a $1 \mathrm{~cm}$, y profundo, siendo la morfología de la sección en «V». La anchura del conjunto es de $40,5 \mathrm{~cm}$ y la altura máxima de $9 \mathrm{~cm}$. Por debajo de este motivo se encuentran unas líneas rectilíneas cuya naturaleza responde a zarpazos de carnívoros.

CS.3. $25 \mathrm{~cm}$ por arriba del anterior y a $170 \mathrm{~cm}$ del suelo se grabó un motivo reticulado. Se sitúa sobre una superficie de morfología cóncava que representa la transición entre la pared y el techo. Se compone de 30 líneas rectilíneas dispuestas entre sí paralela y ortogonalmente (fig. 15, foto 5). La anchura del surco varía de 4 a $5 \mathrm{~mm}$ y la sección presenta morfología en «V». La anchura máxima del conjunto es de $31 \mathrm{~cm}$ y la altura de $35 \mathrm{~cm}$.

CS.4. Una morfología similar a la anterior se localiza en el techo del conducto, a $235 \mathrm{~cm}$ del suelo y a unos $31 \mathrm{~cm}$ del anterior. Se compone de 


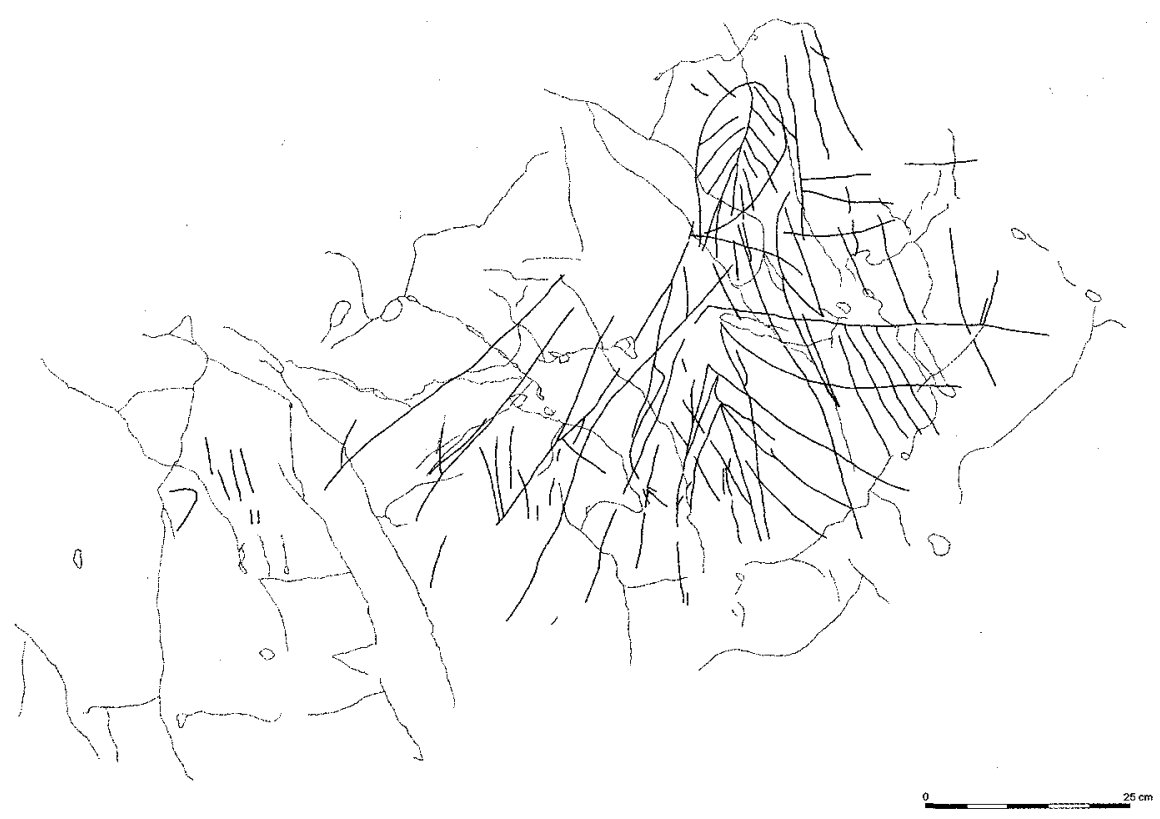

Fig. 13. Motivo CS.1 del sector I de la Cueva del Silo.

14 líneas rectilíneas dispuestas entre sí paralela y ortogonalmente (fig. 16). Los caracteres técnicos son similares a los del motivo CS.3. La anchura máxima es de $19,5 \mathrm{~cm}$ y la altura máxima de $25 \mathrm{~cm}$.

\section{VALORACIÓN DEL DISPOSITIVO GRÁFICO}

Las grafías localizadas en las galerías subterráneas del Sistema Cueva Mayor - Cueva del Silo de la Sierra de Atapuerca vienen a incorporarse al corpus de motivos rupestres existentes en la meseta Castellano-Leonesa (Corchón, Lucas, González-Tablas y Becares, 1988-1989; Gómez-Barrera, 1993).

El reducido conjunto de motivos presentados y el amplio dispositivo iconográfico existente en la Galería del Sílex de Cueva Mayor (Apellániz y Uribarri, 1976), todos ellos considerados de cronología prehistórica postpaleolítica, llevan a reflexionar en torno a dos cuestiones: a) valoración crono-cultural y artística de los motivos y b) relación existente entre evi- 
Grafismo rupestre postpaleolítico en la Sierra de Atapuerca (Burgos): Salón...

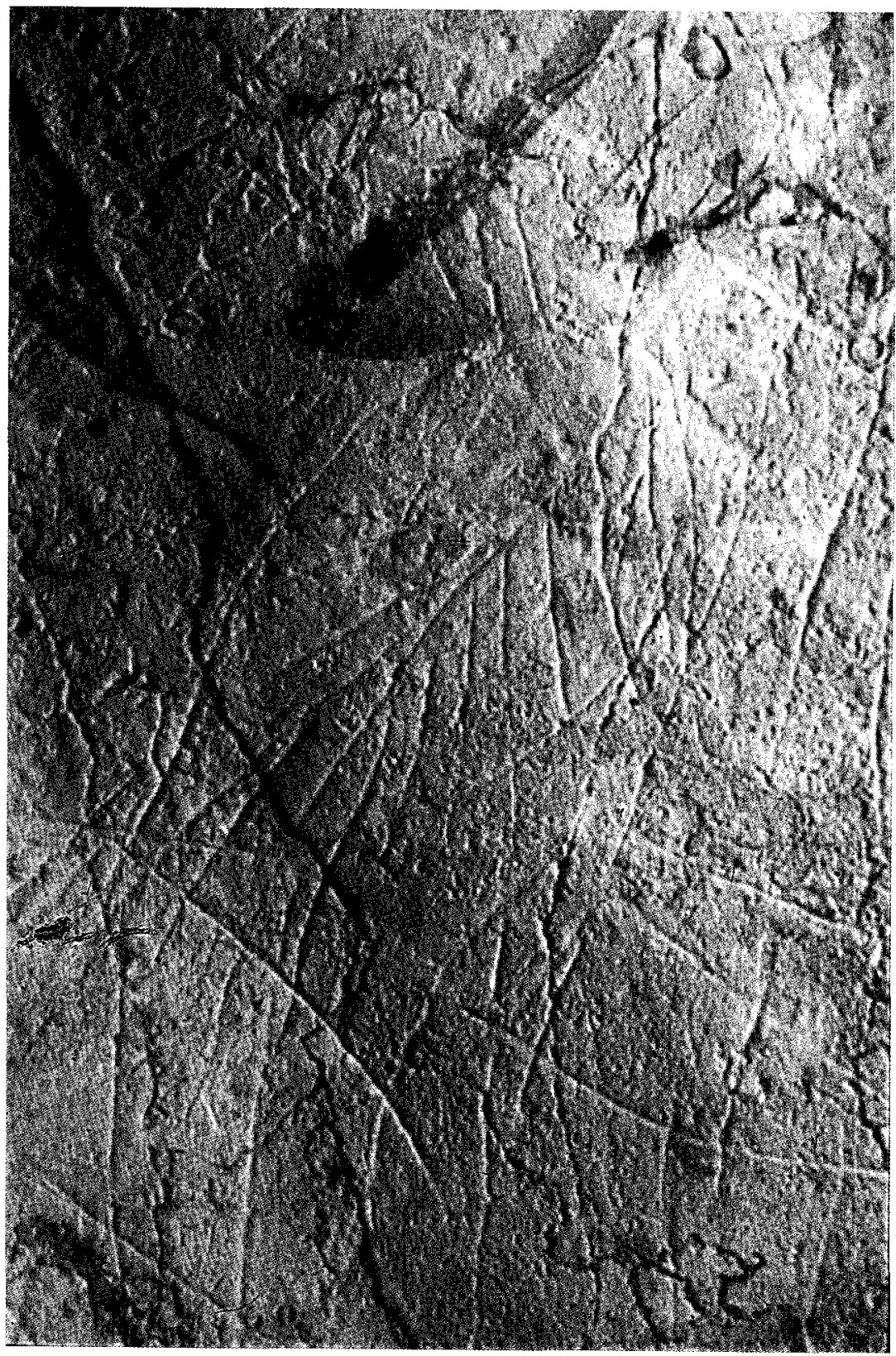

Foto 4. Motivo CS. 1 de la Cueva del Silo. 


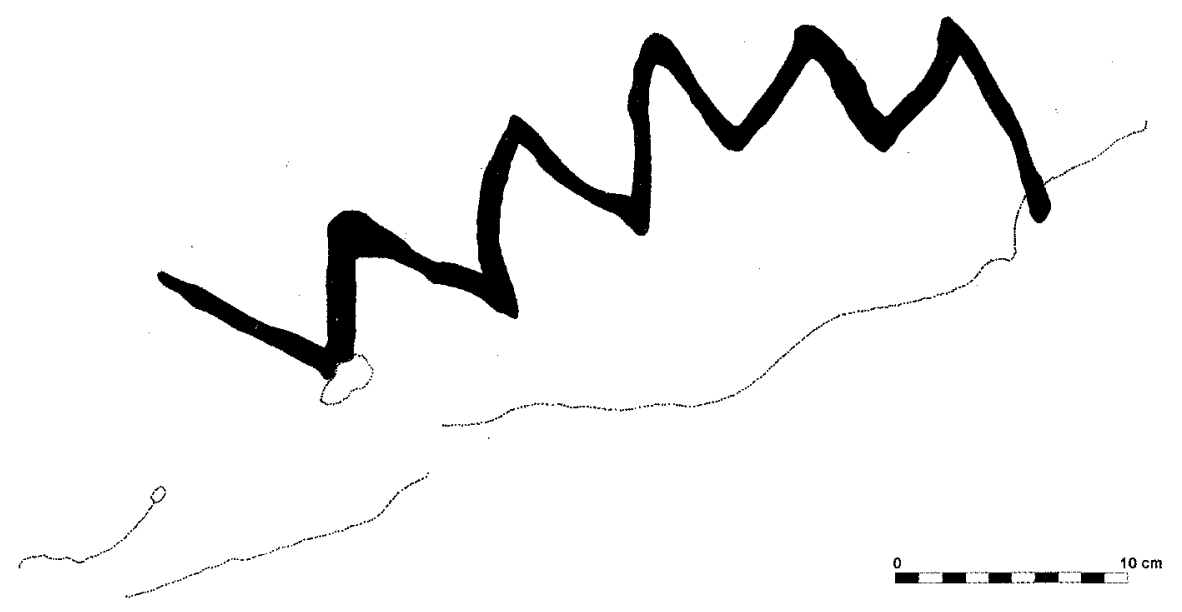

Fig. 14. Motivo CS.2 del sector II de la Cueva del Silo.

dencias gráficas, elementos constructivos, materiales arqueológicos y antropológicos.

\subsection{Valoración crono-cultural y artística de las manifestaciones gráficas}

Desde el punto de vista formal las grafías estudiadas corresponden en su totalidad a representaciones lineales. Éstas presentan una relativa heterogeneidad atendiendo a las disposiciones y relaciones físicas que presentan las líneas, preferentemente rectilíneas. Así, morfologías complejas lineales que aparecen son las retículas, parciales parrillas, zizzag y ramiformes; otros esquemas más simples en su configuración son asociaciones lineales de seriación continua, paralela, que no muestran relación física y convergencia de dos líneas por uno de sus extremos formando un ángulo agudo. No se observan en ninguno de los motivos elementos de juicio para insertar alguno de ellos dentro de los conceptos esquemáticos o abstractos, concluyendo que el grupo estudiado es un grafismo preferentemente lineal, más o menos complejo atendiendo a las relaciones entre líneas, que en algunos casos apunta a construcciones geométricas.

Las manifestaciones se sitúan en paredes extensas, alargadas, disponiéndose éstas por paneles. En el caso de los grabados GS.3 a GS.10 tienden a encuadrarse en diferentes huellas de corriente. La disposición 


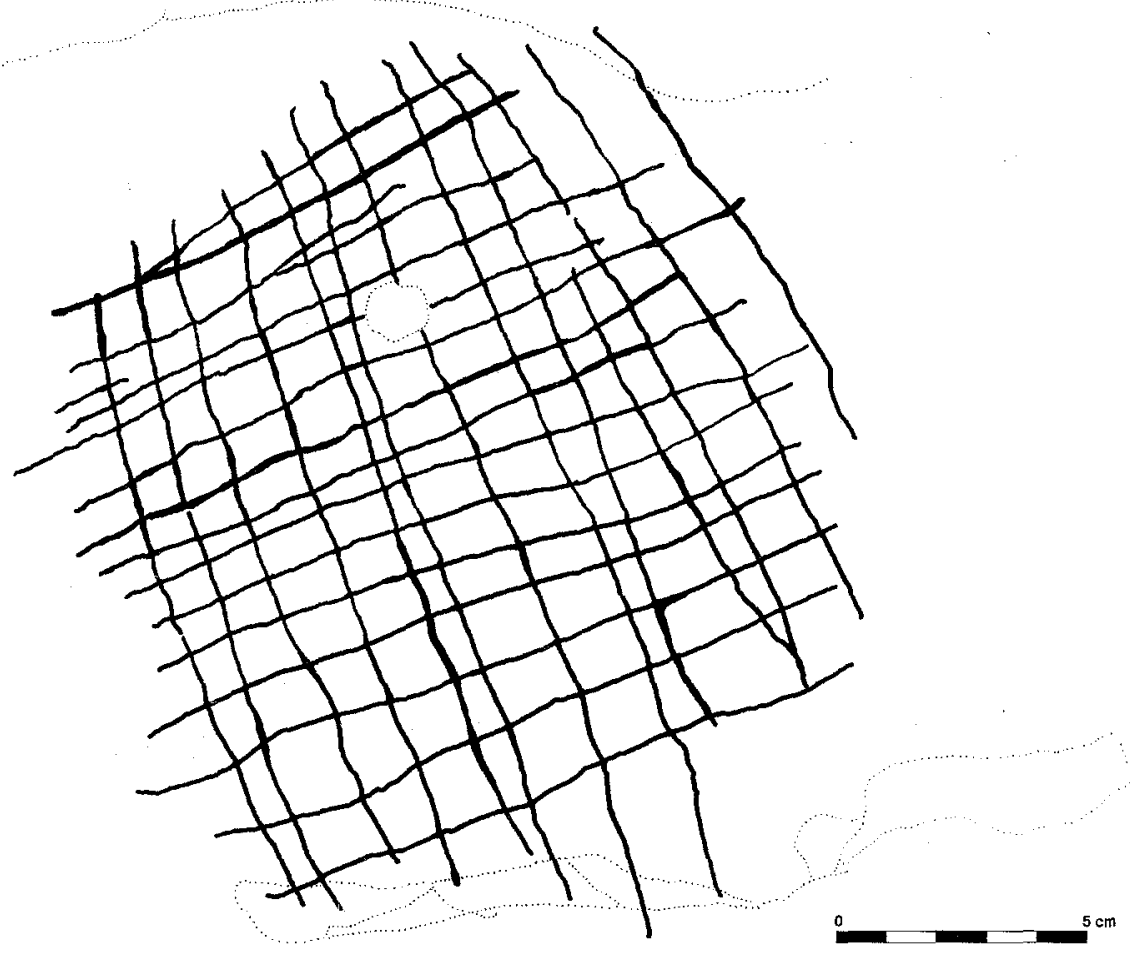

Fig. 15. Motivo CS.3 del sector II de la Cueva del Silo.

del soporte es preferentemente vertical, utilizándose el plano horizontal en las primeras manifestaciones de la Galería del Silo, en un motivo de la Galería Baja y en otro del sector II de la Cueva del Silo.

Las técnicas de representación son el grabado y la pintura. La primera se manifiesta, atendiendo a la configuración del surco, estrecha (en torno a $1 \mathrm{~mm}$ ), poco profundo o superficial y en morfología de sección en " $\vee$ ", apareciendo en la Cueva del Silo, en la Galería del Silo y Galería Baja; en contraposición, los grabados de la Galería de las Estatuas presentan un surco más ancho, más profundo y una morfología de sección en "V" y en «U»; la incisión digital, localizada en la Galería del Silo, muestra surcos anchos y poco profundos con morfología de sección en «U». La pintura, cuyo medio de aplicación no es susceptible de ser estudiado, es de color rojo y forma líneas anchas (entre 1 y $1,5 \mathrm{~cm}$ ). 


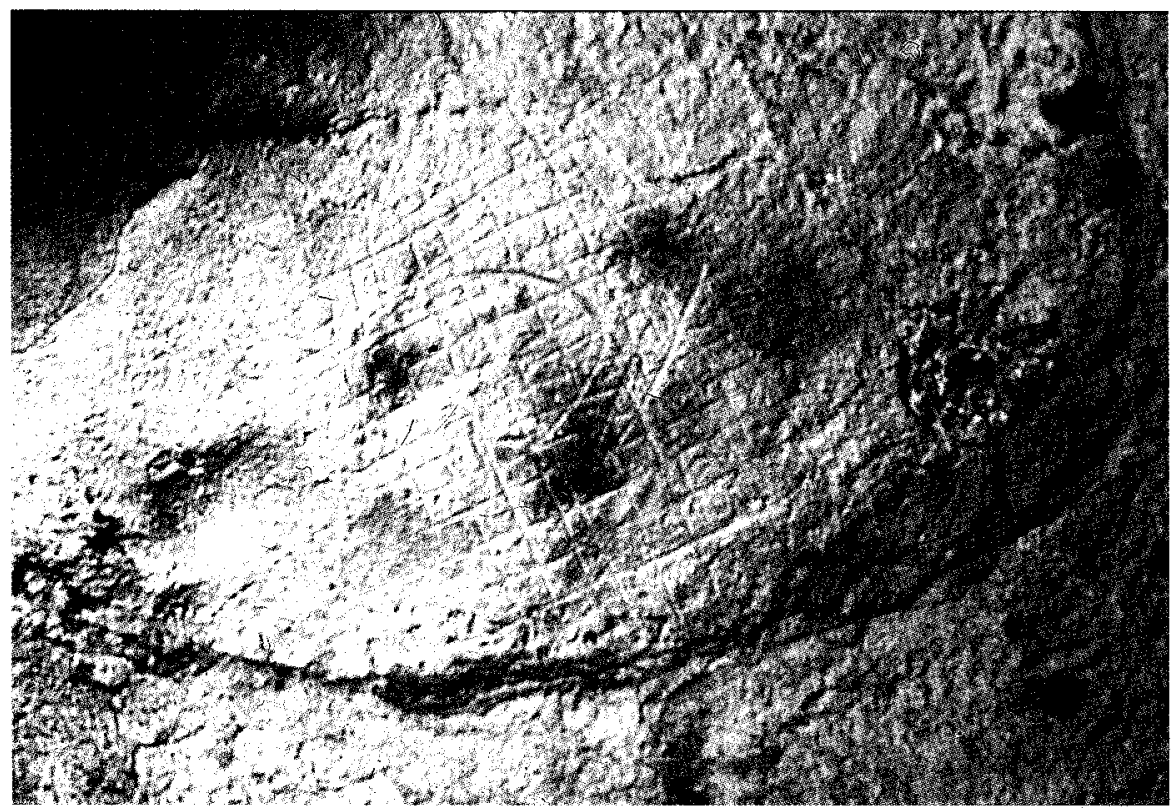

Foto 5. Motivo CS.3 de la Cueva del Silo.

Para el encuadre crono-cultural del dispositivo iconográfico no se dispone en la actualidad de dataciones absolutas directas ni de contexto (tizonazos, cerámicas asociadas, etc.) que puedan servir de reflexión en torno a esta cuestión. Creemos que la posición más justa, a tenor de los datos arqueológicos disponibles y contando con los datos de la Galería del Sílex, es plantear un espectro cronológico amplio de inserción variable entre momentos neolíticos y el final de la Edad del Bronce, sin poder precisar encuadres crono-culturales más precisos.

\subsection{La relación de las evidencias gráficas con otras evidencias arqueológicas}

La Galería del Sílex, el espacio mejor conservado y estudiado, parece corresponderse con un "recinto destinado a acciones de significado simbólico» (Apellániz y Domingo, 1987: 264) de cronología amplia, que va desde el Neolítico avanzado hasta el Bronce Final. Se caracteriza por la abundancia de manifestaciones gráficas, la deposición de elementos cerámicos, restos humanos, algunos de ellos conformando inhumaciones, y 


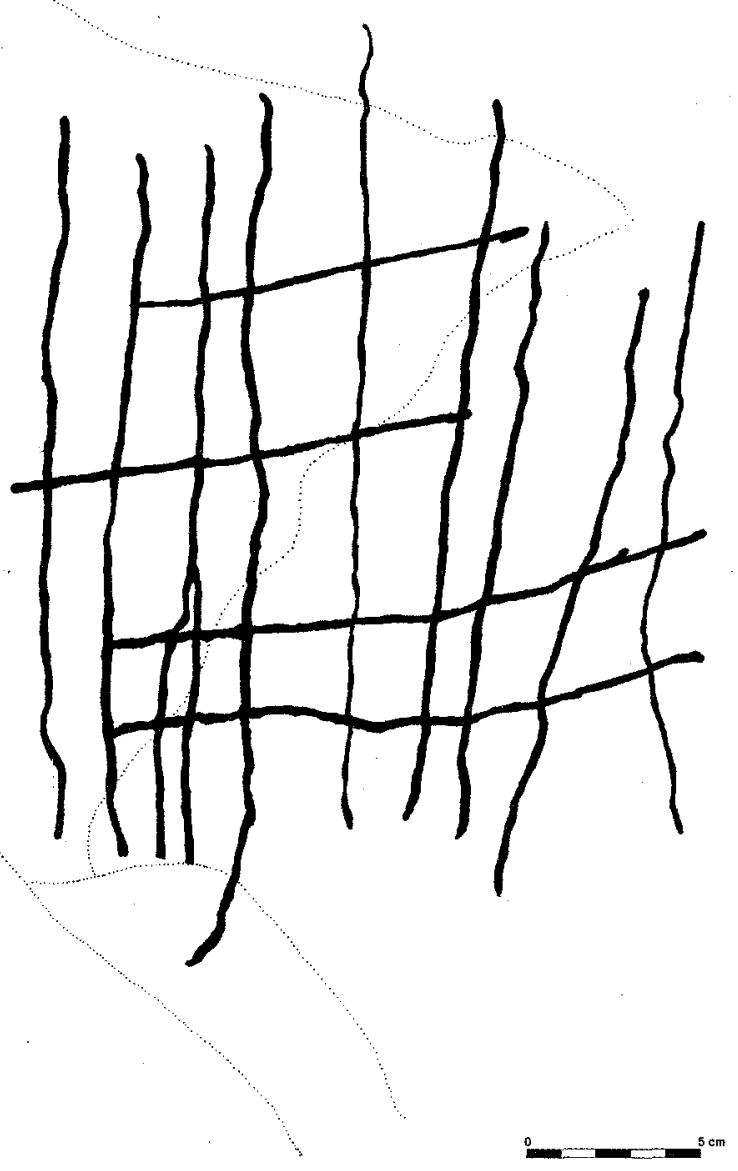

Fig. 16. Motivo CS.4 del sector II de la Cueva del Silo

estructuras antrópicas, identificándose tres tipos de elementos constructivos: los monumentos circulares, los hoyos y una posible "presa». Además, en su interior se ha documentado una explotación de sílex cretácico.

Los monumentos circulares están formados por la disposición circular de piedras ("puede verse una especie de manto de piedras de relativo buen tamaño que forman en algunos puntos unos vacíos circulares, ovales, oblongos o de formas similares a éstas, vacíos en los que las piedras son sustituidas por piedrecilla muy menuda" -Apellániz y Uribarri, 1976: 131—). 
Los hoyos están realizados por técnica extractiva («orificios de forma regular y sección cilíndrica, paredes muy cortadas y regularizadas, el fondo o base liso o plano, y practicados en el suelo de la galería sobre las arenas arcillosas» -Apellániz y Uribarri, 1976: 145-). La posible «presa» está constituida por el levantamiento, junto a una pared de la galería, de un pequeño dique ovalado hecho con fragmentos de concreciones y arcilla, totalmente concrecionado y sobre el que se han formado estalagmitas.

Los anteriores autores han propuesto su funcionalidad sobre la base de criterios contextuales y de presunción: para las primeras se ha apuntado que son «monumentos que representan ofrendas y eso creemos que demuestran los fragmentos de cerámica, el silex y los huesos de animales" (Apellániz y Uribarri, 1976: 143), mientras que en el caso de las extractivas "no hay datos que permitan levantar una hipótesis un poco fundada sobre su sentido y significación, si se exceptúa la de que deben estar en relación con intencionalidades religiosas" (Apellániz y Uribarri, 1976: 145). La funcionalidad de la posible «presa» parece estar avalada por su morfología y por la intensa infiltración que recibe, que ha propiciado la formación de estalagmitas.

Si se intenta establecer una relación entre las manifestaciones gráficas y las constructivas, se ve cómo en la Galería del Sílex se da una cierta asociación de evidencias antrópicas en el sector ocupado por el tipo de monumentos circulares, en donde destaca una de las concentraciones artísticas más significativas, tanto en número como variedad de motivos, entre las que destaca una representación antropomórfica muy similar a otía que compone parte de la decoración de un soporte cerámico. Este sector también destaca por la deposición de cerámicas y restos faunísticos. Por lo que respecta a los hoyos excavados en la arcilla del substrato, indicar que son muy escasos en esta galería y que en principio no presentan relación clara y directa con las grafías.

Cueva Mayor se caracteriza por la existencia de una zona de hábitat situada en el Portalón de entrada y por una serie de galerías, sumamente alteradas en la actualidad, en donde destacan (Galería de las Estatuas, Galería Baja y Galería del Silo) la abundancia de hoyos excavados, una pequeña representación de manifestaciones gráficas y un registro material desigualmente distribuido y mal conservado, que no permite conocer bien su primitivo potencial.

En Cueva Mayor las grafías existentes se localizan en aquellos sectores donde se realizaron hoyos, si se exceptúa la situación manifiesta en el Salón del Coro. Esta asociación es diferente a la detectada en la Galería del Sílex, y a pesar de no conocer su significado, pone de manifiesto una intencionalidad desigual en la agrupación de las evidencias antrópicas. 
La aparición de restos antropológicos puede ser considerada dispar si se compara la Galería del Sílex con el resto del Complejo. De los restos humanos existentes en esta galería se han estudiado 25 individuos ${ }^{4}$ (Galera, 1987) que aparecen en sectores sin muestras gráficas, por lo que en principio no parecen presentar una asociación clara con el arte parietal ( $\sin$ tener en cuenta los restos que permanecen aún sin estudiar en la primera sala, con varios paneles de arte rupestre de temática muy homogénea). En el resto de Cueva Mayor nuevamente debe lamentarse la destrucción de gran parte del contexto prehistórico original, aunque se conocen restos dispersos en la Galería de las Estatuas, Galería Baja y Galería del Silo, por lo que no se puede inferir con garantías la relación existente con las escasas grafías.

A pesar de la destrucción de parte del registro arqueológico, se observa una clara diferenciación de los espacios internos de la cueva, cuya explicación probablemente pueda deberse a una distinta funcionalidad dada a los mismos, predominando en la Galería del Sílex el conjunto cerámico, las muestras iconográficas y los restos humanos, algunos de ellos pertenecientes a inhumaciones, y en el resto de Cueva Mayor las estructuras antrópicas: hoyos y "presas".

La Sierra de Atapuerca ocupa una estratégica posición biogeográfica, en una zona de transición entre las áreas montañosas de la Sierra de la Demanda y Cordillera Cantábrica y los valles más abiertos de los ríos Arlanzón, Vena y Pico, en un sector que posibilita el cómodo tránsito entre la Cuenca del Duero y la Depresión del Ebro. La existencia, en esta sierra, de numerosas cavidades facilitaba la permanencia de hábitats, más o menos continuados, en sus entradas (Portalón de Cueva Mayor y Cueva del Mirador) o su utilización como cavidades sepulcrales (como Cueva Ciega, Cueva del Mirador). Por otra parte, Cueva Mayor presenta una amplia y extensa red de galerías, que ha posibilitado igualmente su utilización como zonas de almacenamiento, lugares de inhumación, de expresión gráfica y de prácticas simbólicas.

La Galería del Sílex es el mejor exponente por combinarse varias de las anteriores funciones. Parece acoger un espacio de función simbólica donde cuestiones simbólicas y de ritual conformen un todo, cuyo significado se nos escapa, con una muy importante representación gráfica que

\footnotetext{
4 El estudio de los restos antropológicos de la Galería del Sílex no consideró las inhumaciones existentes en la primera sala ni las evidencias antropológicas que se observaban al pie del cono de derrubios, evitando así posibles mezclas de materiales en posición primaria con otros en secundaria.
} 
parece tener relación directa con los "círculos de piedra", con la intencional deposición de cerámicas y con los sectores de inhumación, proporcionando todo ello una gran complejidad al conjunto. Por otro lado, la utilización de la galería como lugar de explotación de sílex también queda manifiesta en el tramo final, desconociéndose la relación cronológica entre esta función y la anteriormente referida.

La Cueva del Silo se caracterizaba por presentar un acceso en sima, tal y como señalaban Sampayo y Zuaznávar en su trabajo de 1868. Cuando Breuil, en 1913, visitó la cavidad, ya citó la existencia de una cantera en el sector de entrada, que a mediados de siglo pasado la destruyó dejando configurada la morfología actual de cueva horizontal. Esta entrada originaria dificultaría sensiblemente el acceso a la cavidad, lo que unido a los destrozos de la cantera y de los numerosos visitantes en la segunda mitad del siglo pasado, pueden ser motivos suficientes para la ausencia de evidencias antrópicas, a excepción de las grafías descritas en este trabajo. La dificultad del acceso parece relacionar esta cavidad con un espacio reservado a la representación gráfica, en donde además se localizan las muestras en pequeños conductos laterales, fuera de las galerías principales, dando una clara funcionalidad simbólica a, por lo menos, algunos sectores de la cavidad.

\section{AGRADECIMIENTOS}

Agradecemos al equipo de investigaciones de Atapuerca, y en especial a sus codirectores, la colaboración prestada. A la empresa lberdrola, a quien expresamos su apoyo y colaboración con la dotación, a Ana Isabel Ortega Martínez, de una Beca de Formación de Personal Investigador.

\section{BIBLIOGRAFÍA}

Almagro, M. (1947): “El Paleolítico Español». Historia de España (dir. R. Menéndez Pidal) I, España Paleolítica. Madrid.

ApelLÁNIZ, J. M. y Domingo, S. (1987): Estudios sobre Atapuerca (Burgos) II. Los materiales de superficie del Santuario de la Galería del Sílex. Cuadernos de Arqueología de Deusto n. ${ }^{\circ}$ 10. Servicio de Publicaciones de la Universidad de Deusto. Bilbao.

ApelláNIZ, J. M. y URIBARRI, J. L. (1976): Estudios sobre Atapuerca (Burgos) I. El Santuario de la Galería del Sillex. Cuadernos de Arqueología de Deusto $n .^{\circ} 5$. Servicio de Publicaciones de la Universidad de Deusto. Bilbao.

Breull, H. (1920): “Miscellanea d'Art Rupestre (1)». Boletín de la Real Sociedad Española de Historia Natural, XX, págs. 322-333.

Breuil, H. y Obermaier, H. (1913): «Institut de Paléontologie Humaine. Travaux exécutés en 1912». L'Anthropologie, XXIV, págs. 1-16.

CARBallo, J. (1910): «De Espeleología». Boletín de la Real Sociedad Española de Historia Natural, X, págs. 468-481. 
CoRchón, S.; LucAs, R.; González-TABLAS, F. J. y Becares, J. (1988-1989): «El arte rupestre prehistórico en la región castellano-leonesa (España)». Zephyrus, XLI-XLII, págs. 7-18.

GALERA, V. (1987): «Antropología de las gentes inhumadas en la Galería del Sílex (Atapuerca, Burgos)». Estudios sobre Atapuerca (Burgos), II. Los materiales de superficie del Santuario de la Galería del Sílex (Apelániz, J. M.; Domingo, S.). Cuadernos de Arqueología de Deusto n. ${ }^{\circ}$ 10. Servicio de Publicaciones de la Universidad de Deusto. Bilbao, págs. 279-319.

Gomez-BARRerA, J. A. (1993): Arte Rupestre en la Meseta Castellano-Leonesa. Junta de Castilla y León, Consejería de Cultura y Turismo. Valladolid.

I.T.G.E. (1997): Mapa Geológico de España. Memoria de la hoja n. 200 (19/10). Burgos. Escala 1:50.000. Ministerio de Medio Ambiente. Madrid.

MARCH, L. (1906): «Crónicas burgalesas. Las grutas de Atapuerca». Diario de Burgos, sábado 1 de septiembre, págs. 1-2.

MARTín, M. A.; DOMINGo, S. y ANTón, T. (1981): «Estudio de las cavidades de la zona BU-IV-A (Sierra de Atapuerca)». Kaite, Estudios de Espeleología Burgalesa, 2, págs. 41-76.

Sampayo, P. y Zuaznavar, M. (1868): Descripción con planos de la Cueva llamada de Atapuerca. Burgos. 